\title{
Sobre Berenguer Mercader, anfitrión del Parlament de Joan Roís de Corella, y demás contertulios
}

\section{About Berenguer Mercader, host of the Parlament of Joan Roís de Corella, and other tertullians}

Agustín Rubio Vela rubiovela@yahoo.es

I. $S$.

Resumen: Investigación documental sobre los contertulios del Parlament en casa de Berenguer Mercader, de Joan Roís de Corella: Berenguer Mercader, Joan Escrivà, Guillem Ramon de Vilarrasa, Lluís de Castellví y don Joan de Pròxita; y análisis crítico de los argumentos que han puesto en duda la identidad del batle general como el verdadero anfitrión del encuentro.

Palabras clave: Berenguer Mercader, Joan Escrivà, Guillem Ramon de Vilarrasa, Lluís de Castellví, Joan de Pròxita.

Abstract: Documentary research about the fellow participants in the Parlament en casa de Berenguer Mercader, by Joan Roís de Corella: Berenguer Mercader, Joan Escrivà, Guillem Ramon de Vilarrasa, Lluís de Castellví and don Joan de Pròxita; and critical analysis of the arguments put forward to question the identity of the batle general as actual host of the meeting

Keywords: Berenguer Mercader, Joan Escrivà, Guillem Ramon de Vilarrasa, Lluís de Castellví, Joan de Pròxita.

\footnotetext{
* Este trabajo se inscribe en el proyecto del MICINN (Ministerio de Ciencia, Innovación y Universidades) «La cultura literaria medieval y moderna en la tradición manuscrita e impresa (VI)", Ref. FFI2017-83960-P (AEI/FEDER, UE).
} 
Agustín Rubio Vela. Sobre Berenguer Mercader, anfitrión del Parlament de Joan Roís de Corella, y demás contertulios

El Parlament o col Lació que aprés de sopar sdevench en casa de Berenguer Mercader entre alguns hòmens d'estat, de Joan Roís de Corella, es una obra literaria que invita especialmente a adentrarse en la rica documentación de la Valencia del siglo XV. Concebida por el poeta teólogo como una culta tertulia aristocrática entre amigos, de la que él se erige en cronista, se van sucediendo las intervenciones de aquéllos, cada uno de los cuales recita en prosa un relato mitológico, «una ovidiana faula», cinco en total, a los que Corella da forma con su peculiar estilo (Riquer 1980: 313-315). Aunque pudo ser una ficción poética y no un encuentro celebrado realmente (Guinot: 1921, 21 y 23), los contertulios son personajes reales: Berenguer Mercader, Joan Escrivà, Guillem Ramon de Vilarrasa, Lluís de Castellví y don Joan de Pròxita; de ahí que pueda afirmarse que la obra se nos presenta «en un context versemblant $i$ identificable amb la realitat concreta»(Martos 2001: 111). Lo cual ha sido un incentivo para la investigación histórica interesada en proyectar luz sobre el bello texto prerrenacentista, cuyo conocimiento, obviamente, será tanto más profundo cuanto más se sepa del entorno social y cultural del autor en el momento en que lo creó. Y, efectivamente, en los dos últimos decenios, las noticias documentales relativas al selecto conjunto de amigos de Corella, amantes de la mitología clásica, han sido objeto de búsqueda y de análisis por parte de varios estudiosos.

\section{La cuestionada identidad de Berenguer Mercader}

La mansión del batle general del reino de Valencia, Berenguer Mercader, se ha considerado tradicionalmente el escenario elegido por Roís de Corella para su célebre obra. «Els personatges que hi intervenen, reunits a la casa que aquest important 'home d'estat', batlle general del regne de València i senyor de la Foia de Bunyol, tenia al carrer de Cavallers de València, són tots membres de la noblesa valenciana». Las anteriores palabras de Jordi Carbonell (1983: 17-18) resumen una idea compartida y aceptada de manera unánime por la historiografía de la pasada centuria. Si Joan Fuster se refería en 1962 (351-352) a los contertulios de «cognoms tan aristocràtics com Escrivà, Vilarrasa, Castellví, Pròixita», que «s'aplegaven al domicili del pròcer Berenguer Mercader», esto es, a «la casa d'un Mercader que pertanyia a la casa dels senyors de Bunyol», en 1964, Martí de Riquer aludía a éste como la «persona important», «en la casa del qual, al carrer dels Cavallers, tingué lloc la vetllada literària», que él situaba cronológicamente antes de 1469/1471 (1980: III, 314 y 315). Y Curt Wittlin podía escribir en 1998: «Molts dels meus lectors saben qui era Berenguer Mercader. No tant perquè havia estat Batlle de València, sinó perquè fou l'amfitrió d'aquell famós dinar amb sobretaula literaria que ens descriu Joan Roís de Corella» (1998: 93).

Hijo del jurista misser Joan Mercader, a quien Fernando I designó batle general del regne de València en octubre de 1412, Berenguer, propietario de la baronia de Buñol desde 1425 (Tintó Sala 1979: 21 y 29), fue cabeza de su linaje a partir del 29 de noviembre de 1443, cuando falleció su padre y heredó la casa familiar de la calle dels Cavallers, situada en el lugar que ocupa actualmente el palacio de los condes de Buñol o marqueses de Mercader (Simó \& Teixidor de Otto 1996: 151-157; Garín Ortiz

SCRIPTA, Revista internacional de literatura i cultura medieval i moderna, núm. 14 / desembre 2019 / pp. 1 - 33 ISSN: 2340-4841 · doi:10.7203/SCRIPTA.14.16357 
Agustín Rubio Vela. Sobre Berenguer Mercader, anfitrión del Parlament de Joan Roís de Corella, y demás contertulios

de Taranco 1983: 136). Tres años antes le fue transferida la batlia general por su progenitor, con la aquiescencia del rey. Permaneció en el oficio hasta 1467, fecha en la que, al igual que hiciera su padre, cesó por voluntad propia en favor de su primogénito, Honorat Berenguer Mercader, quien lo desempeñaría hasta 1485. Murió en 1471 (Rubio Vela 2013: 603-606).

Corella pudo compartir afinidades estéticas con el prócer, que en su juventud había estado en tierras itálicas. Por ello, refiriéndose a éste, escribió Riquer: «Res no té d'estrany que persona d'aquestes característiques es complagués a reunir a casa seva uns quants amics, més joves que ell, per debatre temes mitològics». Como anciano pater familias, habría sido el anfitrión de aquellas personas cultas, con la mayoría de las cuales, además, estaba unido por lazos de parentesco: «era gairebé una tertúlia familiar. La presidia l'amfitrió, Berenguer, que devia ésser molt vell». Y añadía el maestro: «hi assistien Joan de Próxita (germà de Tomàs de Próxita casat ja el 1468, amb Yolant Mercader, filla de Perot Mercader i néta de Berenguer), Lluís de Castellví, gendre dels fills de Berenguer i cunyat de Joan Escrivà; i ja hem vist que Corella podia ésser llunyà parent dels Mercader». La excepción sería Guillem Ramon de Vilarrasa, «l'únic que no trobo lligat a la família amb llaços de parentia» (Riquer 1980: III, 315).

Hoy, sin embargo, se pone en duda que el Berenguer Mercader del Parlament fuese el batle general. La razón principal es que, en tiempos de Joan Roís de Corella, se localizan otros dos personajes homónimos, más jóvenes que aquél y miembros de su familia, que tuvieron relación con el poeta: el caballero mossén Berenguer Mercader, señor de Argelita, y el doncel En Berenguer Mercader. ${ }^{1}$ El primero podría ser el que acogió en su casa a los contertulios, según Josep Guia i Marín (2003), autor que no descarta por completo que el anfitrión fuera el doncel, pero que considera «mancada d'un mínim suport documental» y «absolutament inversemblant per a qui investigui la vida valenciana de la segona meitat del XV» su identificación con el batle general. No obstante, deja abierta una posibilidad: "Tanmateix, caldrà continuar-hi la recerca, sense descartar la hipotètica troballa d'alguna dada positiva que permeti suposar una relació d'amistat, pels voltants de 1460, entre el vell Berenguer Mercader, batlle general, i el jove Joan Roís de Corella, futur gran escriptor».

Una década después, en un estado de la cuestión, Antoni Ferrando tomaba nota del cuestionamiento de la visión tradicional, manifestando cierto escepticismo sobre la exclusión del prócer: «Tot i amb això, no podem excloure que l'amfitrió fos el ja llavors sexagenari batle general, el més famós dels tres» (Ferrando Francés 2013: 641). Y un año más tarde, Chiner Gimeno (2014: 165) escribía: «ara com ara no existeixen suficients proves documentals per a determinar, sense cap mena de dubte, si l'amfitrió d'aquesta fictícia tertulia literària referida per Corella és el vell Batle General del regne de València Berenguer Mercader - postura tradicional des d'època de Riquer (1964)- o bé és un dels dos joves Berenguer Mercader assenyalats per Guia (2003)». En la misma fecha, Abel Soler también

1 Este último era conocido por Riquer, que lo descartaba con estas palabras: «però no pot ésser l'hoste del Parlament per tal com [...] aquest fou redactat per Joan Roís de Corella quan encara no era mestre en Teologia, la qual cosa fa que no pugui ésser posterior al març del 1471, com a màxim» (1980: III, 315).

SCRIPTA, Revista internacional de literatura i cultura medieval i moderna, núm. 14 / desembre 2019 / pp. 1 - 33 ISSN: 2340-4841 ·doi:10.7203/SCRIPTA.14.16357 
Agustín Rubio Vela. Sobre Berenguer Mercader, anfitrión del Parlament de Joan Roís de Corella, y demás contertulios

negaba que fuese el batle general el dueño de la casa del encuentro corelliano. A su juicio, habría sido el doncel homónimo -el tercer y más joven Berenguer Mercader- quien actuó de anfitrión en torno a 1462, año en el que «pensem que seria molt encertat datar la redacció del Parlament», obra que «reflecteix molt bé l'ambient cultural de la ciutat cap al 1460» (2014: 253 y 256). ${ }^{2}$

\section{El argumento de la edad}

Los argumentos que se han esgrimido para descartar o poner en duda que fuese el batle uno de los contertulios se enmarcan en una interpretación de la expresión «en vida e entendre conformes» con que éstos son presentados en la obra. Según Guia i Marín (2003), el Parlament, «tant si va ser real com si va ser una ficció de Corella, implica unes relacions de coneixença i fins i tot d'amistat entre els intervinents, que hi són presentats com de vida e entendre conformes». Puesto que el prócer tendría «pels voltants del 1460» más de setenta años, no sería verosímil que fuese él quien estuviera «en alegre companyonia 'de vida e entendre conformes', amb una jove promesa de la teologia i la literatura, Joan Roís de Corella, de menys de vint-i-cinc anys». Y, dada la inexistencia, hoy por hoy, de documentación que relacione directamente al batle con Corella, considera el autor que lo más razonable es pensar que el Berenguer Mercader del Parlament fue el señor de Argelita, «i que l'obra va ser escrita en la dècada dels vuitanta», por haber tres documentos que indican por esas fechas la existencia de una relación de amistad entre él y el poeta.

Así pues, como la frase «en vida e entendre conformes», referida a los contertulios, «suggereix que devien ser d'edat aproximada»-son palabras de Ferrando Francés-, ha sido interpretada en un sentido de amistad generacional: «companys de generació, d'estudis i d'aficions literàries», según el citado autor, que considera razonable «situar la hipotètica tertúlia en casa de Berenguer Mercader abans de gener de 1459, és a dir, quan Corella encara tenia 23 anys i quan els altres contertulians no devien allunyar-se massa anys d'aquesta edat» (2013: 639 y 640). Admite, no obstante, la posibilidad de que el batle fuera la excepción entre un conjunto de jóvenes: «Aquestes succintes dades biogràfiques ens permeten confirmar que tots els components de la tertúlia de la casa de Berenguer Mercader -en tot cas llevat d'aquest- devien ser relativament joves, al voltant dels 25 anys». En tal caso, si el anfitrión del «cercle de lletraferits de la casa de Berenguer Mercader» fuera el prócer, habría que interpretar el sintagma «en vida e entendre conformes», no en un sentido generacional, sino sólo «en el sentit que tots el contertulians (...) compartien unes mateixes afinitats literàries» (Ferrando Francés 2013: 644). De hecho, era esto lo que Riquer sostenía cuando afirmaba que nada tenía de extraño que el viejo batle se complaciera en reunir en su casa «uns quants amics, més joves que ell, per debatre temes mitològics».

Para Abel Soler, juventud y amistad adquieren una dimensión explicativa del cónclave poético, «un sopar d'amics que són homes d'estat», que describe así: «quatre donzells novençats -acabats de

2 En la p. 255 precisa: «setembre del 1461 [...] ens pot servir de data post quen»».

SCRIPTA, Revista internacional de literatura i cultura medieval i moderna, núm. 14 / desembre 2019 / pp. 1 - 33 ISSN: 2340-4841 $\cdot$ doi:10.7203/SCRIPTA.14.16357 
Agustín Rubio Vela. Sobre Berenguer Mercader, anfitrión del Parlament de Joan Roís de Corella, y demás contertulios

casar-, un cavaller -Corella-, que n'esdevé cronista, i un noble baró lletraferit», Joan de Pròixida. Uno de esos cuatro «donzells o generosos: persones de llinatge noble i relativament joves, que no han professat encara en l'orde de cavalleria», y que, como homes d'estat, «s'acaben d'estrenar en la vida pública i política de la ciutat», sería el anfitrión. No el viejo batle, sino el joven doncel (2014: 254,256 y 276).

El adverbio relativament de la frase anterior no debe pasar inadvertido, como tampoco este otro, majoritariament, que aflora en otro párrafo del último de los autores citados: «observarem que els del Parlament, majoritàriament, eren joves novençans, d'edat molt acostada a la de Joan de Corella» (Soler 2014: 254). Con ambos adverbios reconoce, de manera discreta, que el grupo, en cuanto a la edad, no era homogéneo. Lo mismo que cuando alude a «el perfil de la majoria dels homes d'estat convocats». Y es que no todos los participantes eran jóvenes; al menos uno, Pròxita, era persona mayor, según los datos biográficos que proporciona el propio autor -«Joan de Pròixida i Calataiud (c. 1420-1476)» (Soler 2014: 273)-, de acuerdo con los cuales tendría unos cuarenta y dos años en 1462. Era, por tanto, más de tres lustros mayor que Corella. Soler no resalta el dato. Prefiere decir que los otros eran más jóvenes: «Joan de Pròixida és un personatge que respon, igual que els altres més joves i més formats, al perfil d'home d'estat». Algo parecido se percibe en esta otra frase: «Des del punt de vista - diguem-ne- sociològic, Pròixida és noble baró -cavaller-i Corella és un cavaller jovençà». Los matices - «relativament», «majoritariament», «la majoria»— indican una evidencia: no todos eran jóvenes de edad similar al poeta. Al menos uno, Pròxita, era mayor que él. Lo reconoce el autor al justificar su intervención en el último lugar: era «el major de tots i el més noble de sang o de llinatge: per això parla l'últim»; su cometido en la tertulia sería «suplir los defalliments dels joves amb la seua acreditada experiència» (Soler 2014: 255-256).

Ahora bien, el perfil de edad de la «colla d'amics» no es un dato más, sino un argumento. Un argumento que utiliza Soler para descartar al batle Mercader como uno de ellos por no ajustarse a ese perfil. Lo excluye ya de facto cuando escribe «en Vila-rasa, en Castellví, en Mercader i n'Escrivà»(2014: 256) -es obligado decir que en el Parlament, jamás se les antepone ese «en» a los nombres de estos contertulios-, refiriéndose a los participantes que presupone no caballeros. Lo que supone asimismo la exclusión del otro mossén Berenguer Mercader -el sobrino homónimo al que Guia considera el más probable de los posibles anfitriones-, puesto que era miles. Soler, en el caso de este último, afirma que "per raons d'edat no encaixa amb el perfil de la majoria dels homes d'estat convocats» (Soler 2014: 258-259).

Los dos caballeros Mercader son descartados por no encajar en una reunión de jóvenes a la que, sin embargo, asistió don Joan de Pròxita, que no lo era. Es obvio que la presencia de éste, incuestionada e incuestionable, rompe el perfil generacional del grupo, al tiempo que revela la insostenibilidad del argumento: si fueran todos jóvenes, cabría poner en duda que el batle Mercader participara en el cónclave; pero ese perfil homogéneo era inexistente, por lo que carece de validez argumental la edad para descartar por su edad a Berenguer Mercader. Si éste era «un home d'una altra generació 
Agustín Rubio Vela. Sobre Berenguer Mercader, anfitrión del Parlament de Joan Roís de Corella, y demás contertulios

i amb un bagatge literari distint al de Corella» (Soler 2014: 257), lo mismo se puede afirmar de Pròxita. Pese a ello, no duda el autor en excluir al primero por razones generacionales: «Si fóra ell [...] tindria ja més de 60 anys i múltiples ocupacions, cosa que fa difícil pensar en ell com un home en vida e entendre conforme amb la resta d'amics de mossén Corella». ${ }^{3}$

\section{La edad del doncel}

Si al menos - dejando de momento al margen el caso de Pròxita-, el doncel Mercader fuera de una edad próxima a la de Joan Roís de Corella, tendría cierta verosimilitud la hipótesis de Soler. Pero un análisis documental pone de manifiesto, según vamos a ver, que no es así. Los datos de que disponemos hoy acerca de aquél, «el candidat més ajustat i creïble per a fer d'amfitrió de la colla d'amics de c. 1462» para Soler (2014: 260-261), y para Guia no descartable, cuestionan igualmente esa posibilidad.

Hijo de Galceran Mercader, en una transacción censal realizada el 17 de julio de 1472, se presenta a sí mismo - «ego, Berengarius Mercader, generosus, habitator civitatis Valentie»como propietario de unos censos que en 1457 había comprado su padre al gobierno municipal: «originaliter onerati fuerunt magnifico Galcerando Mercader, militi, patri meo». Pasaron a él al morir su progenitor, que lo declaró heredero en el testamento - «in et cum quo heredem suum instituit me, dictum Berengarium, filium suum»-, realizado en Buñol el 15 de agosto de 1459 y publicado tras el óbito los días 11 y 14 de noviembre de ese mismo año «in loco del Puig e de Argilita». ${ }^{4}$ La documentación emanada a raíz de la transacción censal insiste en ello -«En Berenguer Mercader, donzell, habitador de la dita ciutat», propietario de censos «originalment carreguats [...] a l'honorable mossén Galceran Mercader, cavaller»-, e informa, además, de que en 1463 «lo dit En Berenguer Mercader és fet magor de XX anys, e àbil e sufficient a regir si e sos béns», por lo que a partir de esta fecha dejó de estar bajo tutela de «mossén Berenguer Mercader, batle general e En Pere Garró, lochtinent de aquell», a quienes Galceran, en «son derrer testament, fet en Bunyol [...], lexà en tudors e curadors» de su hijo y heredero. ${ }^{5}$

3 Frase ésta (Soler 2014: 258) en la que el autor recurre a un argumento inane, las «múltiples ocupacions» que habrían impedido al batle general celebrar en su casa la tertulia literaria, con el agravante de que incurre de nuevo en el inaceptable error metodológico de dar por supuesto algo que habría que demostrar: en este caso, la fecha de 1462 en que «sería molt encertat» datar la redacción el Parlament. Cabe recordar que desde 1467 hasta su muerte en 1471, Berenguer Mercader no fue batle, por lo que estaría libre de tan absorbentes trabajos.

4 Archivo Municipal de Valencia [AMV], Protocols, Jaume Ximeno II, t-3, s. fol. (1472, julio, 17); ibid., t-4, s. fol. (1472, julio, 17); ibid., t-5. s. fol. (1473, junio, 12 y 22, y julio, 31); ibid., 8-5, f. 143v (1473, julio, 31).

5 AMV, Claveria Comuna [CC] O-39, ff. 93v-94v (1472, septiembre, 22). Un año antes realizó otra transacción de rentas censales originariamente compradas el 9 de diciembre de 1435 por Isabel, viuda de Pere Mercader, procuradora de su hijo, el entonces doncel Berenguer Mercader, quien el 19 de abril de 1447, siendo ya caballero («Deinde autem

SCRIPTA, Revista internacional de literatura i cultura medieval i moderna, núm. 14 / desembre 2019 / pp. 1 - 33 ISSN: 2340-4841 · doi:10.7203/SCRIPTA.14.16357 
Agustín Rubio Vela. Sobre Berenguer Mercader, anfitrión del Parlament de Joan Roís de Corella, y demás contertulios

Berenguer quedó huérfano muy joven. Su minoría de edad duró hasta 1463, año en que dejó de ser tutelado. De ahí que hasta entonces las rentas censales de las que era propietario fueran entregadas a sus tutores, uno de los cuales era el batle. ${ }^{6}$ En los años 1461 y 1462 figura en la documentación como «Berenguer Mercader, pubil». ${ }^{7}$ Así pues, en 1462, fecha en torno a la cual considera Soler «que seria molt encertat datar la redacció del Parlament», el doncel a quien él considera el verdadero anfitrión del cónclave, era un menor huérfano de diecinueve años, que aún se encontraba bajo tutela del batle Mercader y del lugarteniente de éste, Pere Garró, que en el futuro sería su suegro. ${ }^{8}$ La acusada diferencia de edad con respecto a Corella, que tendría unos veintisiete años -Pròxita unos cuarenta y dos, según los datos del citado autor- contradice de nuevo la visión generacional de los contertulios, que no se sostiene ni siquiera en caso de aceptar que el doncel fuera uno de ellos.

\section{4. ¿Jóvenes recién casados?}

Otro dato que llama la atención es la fecha en que contrajo matrimonio: «El donzell Berenguer Mercader -que després veurem que deu ser el del Parlament- es casà pel 1460»; «Es casà cap al 1460 amb Joana, la filla i hereva universal del ciutadà Pere Garró (+1479)» (Soler 2014: 256 y 260). Si fuera así, se habría casado con diecisiete años, cuando todavía era menor de edad. Lo cual podría haber ocurrido, si no fuera por que, según hemos visto, él, en 1462 todavía es calificado de 'pubil', y la que sería su mujer, todavía en septiembre del año siguiente era una doncella bajo tutela paterna, como demuestra la siguiente orden de pago de los jurats de Valencia al clavari dels censals: «Los jurats, etc. Pagats a Na Johana, donzella, filla de l'honorable En Pere Garró, lochtinent de batle general de regne de València, e per ella al dit honorable En Pere Garró, pare, tudor e curador de aquella, CC sous reyals, deguts del XII dia del proppassat mes de agost, per censal que ha sobre la dita ciutat cascun any lo dit dia, segons, etc. E cobrats, etc. Data Valentie VII ${ }^{a}$ die septembris anno a nativitate Domini $M^{\circ}{ }^{\circ} C C{ }^{\circ} L X I I I^{\circ}$ : CC sous». ${ }^{9}$

dictus Berengarius Mercader, dierum minor, tunc domicellus et tempore venditionis dicti censualis honore et privilegio militari insignitus»), lo vendió al que todavía era doncel Galceran Mercader, padre de Berenguer, de quien éste lo heredó (id., Protocols, Jaume Ximeno II, t-3, s. fol.; 1471, mayo, 30).

6 El 13 de octubre de 1460, el clavari recibía orden de pagar la renta censal «a Berenguer Mercader, fill e hereu de l’honorable Galceran Mercader, cavaller, quondam, e per ell als honorables mossén Berenguer Mercader, batle general de regne de València e En Pere Garró, lochtinent del dit batle, tudors e curadors de aquell» (AMV, Claveria Censal [CCe] I-77, f. 32r).

7 AMV, Protocols, Jaume Beneyto, r-18, s. fol. (1461, noviembre, 13; 1462, agosto, 16; 1462, diciembre, 23).

8 El 1 de febrero de 1486, «ego, Ioana Garró, uxor magniffici Berengarii Mercader, generosi, locumtentis baiuli generalis regni Valentie», decía ser propietaria de unos censos «originaliter onerati magniffico Petro Garró, civi dicte civitatis et locumtentis baiuli generalis dicti regni, quondam genitori meo...» (AMV, Protocols, Jaume Ximeno II, t-18, s. fol.; 1486, febrero, 1).

9 AMV, CCe I-80, f. 18 r.

SCRIPTA, Revista internacional de literatura i cultura medieval i moderna, núm. 14 / desembre 2019 / pp. 1 - 33 ISSN: 2340-4841 · doi:10.7203/SCRIPTA.14.16357 
Agustín Rubio Vela. Sobre Berenguer Mercader, anfitrión del Parlament de Joan Roís de Corella, y demás contertulios

Pero lo más sorprendente, desde una perspectiva científica, es que Soler no documente ese inauténtico dato cronológico del matrimonio. Lo afirma, sin nota alguna a pie de página, sin la preceptiva referencia, documental o bibliográfica, que autorice a hacerlo. Y ello, a pesar de que no se trata de un dato cualquiera, sino de otro dato argumental, pues nos presenta el coloquio «com una conversa d'homes casats i 'en port segur', és a dir, practicants d'un amor honest i conjugal», cuya redacción «seria molt encertat datar [...] cap al 1462, quan tots els participants, després d'anar follament navegant per la tempestuosa mar de Venus, es trobaven ja resguardats en port seguns (Soler 2014: 255).

Uno de los fundamentos de tal interpretación es la proximidad de los casamientos de cuatro de los jóvenes participantes, «quatre donzells novençats -acabats de casar-» (Soler 2014: 276), uno de los cuales sería el doncel Berenguer. Otro sería Joan Escrivà, quien se habría casado en 1461, según asegura, sin ambages, e igualmente sin aportar la obligada referencia que respalde el aserto: «Joan Escrivà es casà el 1461 amb Beatriu de Montpalau, germana menor de Violant, la muller de Lluís de Castellví». En esta ocasión, el dato, que el solo hecho de esgrimirlo sin respaldo obliga, en rigor, a cuestionarlo, puede afirmarse que es erróneo. En efecto, consta documentalmente, y así se ha publicado (Parisi 2008-2009: 71; Rubio Vela 2014: 52), que la firma de las cartas nupciales de Joan Escrivà y Beatriu de Montpalau tuvo lugar el 23 de julio de 1479, esto es, dieciocho años después de lo que asegura Soler. ${ }^{10}$

Una vez hechas estas precisiones, observemos detenidamente la frase: «El donzell Berenguer Mercader -que després veurem que deu ser el del Parlament- es casà pel 1460. Escrivà i Vila-rasa es casaren el 1461; Castellví, en gener del 1462. Corella mantingué el seu idil li amorós, amb convivència honesta i quasi matrimonial, el 1462 o el 1463. Don Joan -també casat- era el major de tots...» (Soler 2014: 256). Pues bien, de los cuatro casos señalados de donceles jóvenes recién casados, al menos dos -Mercader y Escrivà- no lo estaban. Si tampoco era recién casado el caballero Pròxita, y el poeta Corella nunca contrajo matrimonio, ¿qué hay de realidad y qué de invención en la afirmación: «els del Parlament, majoritàriament, eren joves novençans, d'edat molt acostada a la de Joan de Corella» (Soler 2014: 254)?

10 En el libro de quitaments del año 1481-82, el clavari dels censals registra la entrega «als magnífichs mossén Johan Ram Scrivà, cavaller, habitador de la dita ciutat, e a Na Beatriu, muller sua», del dinero correspondiente al valor de ese censo, comprado en 1416 por «mossén Berenguer Selelles, cavaller», heredado en 1446 por Joan de Montpalau, doncel, y a la muerte de éste por su hijo Salelles de Montpalau, quien lo transfirió «al dit magníffich mossén Johan Ram Scrivà, cavaller, en pagua rata de la dot de la damunt dita magnífica Na Beatriu, jermana del dit mossén Selelles, ab lo dit mossén Johan Ram, segons se mostra ab cartes nubcials rebudes per lo dit honorable N'Anthoni Barreda, notari, a XXIII de joliol de l'any MCCCCLXXVIIII, segons en les dites cartes és larch contengut» (AMV, Quitaments de Censals W-8, ff. 53r-54r). Joan Ram Escrivà no es otro que Joan Escrivà (Rubio Vela 2014: 48). 
Agustín Rubio Vela. Sobre Berenguer Mercader, anfitrión del Parlament de Joan Roís de Corella, y demás contertulios

\section{E1 caballero homónimo del batle}

El 5 de mayo de 1425, en Valencia, Pere Mercader, sintiendo próxima la muerte, hizo testamento ante el notario Antoni Pasqual, que fue publicado el 23 de julio de ese año. En él «instituí hereu seu universal Berenguer Mercader, pubil, fill seu, e assignà-li en tudors e curadors de aquell l'honorable micer Johan Mercader, doctor en leys, batle general del regne de València, e los honorables mossén Berenguer Mercader, cavaller, e En Perot Mercader, donzell, habitadors de València». ${ }^{11}$ Así pues, en 1425, Pere encomendó a su hijo Berenguer a tres familiares próximos: el batle misser Joan Mercader, mossén Berenguer Mercader y En Perot Mercader. En los años siguientes, las rentas de las que el huérfano era propietario eran pagadas a sus tutores por el clavari dels censals: «pagats a $\mathrm{N}$ Berenguer Mercader, pubil, fill e hereu de l'honorable mossén Pere Mercader, cavaller, quondam habitador de la dita ciutat, e per ell als honorables micer Johan Mercader, doctor en leys, batle general del regne de València, mossén Berenguer Mercader e mossén Perot Mercader, cavallers, habitadors de la dita ciutat, tudors e curadors de aquell...» ${ }^{12}$ A comienzos de 1441, el huérfano era elevado a la condición de caballero. ${ }^{13}$ Era el año en que cumplía veinte: «Berenguer Mercader, hereu e pubil qui dessús, és fet cavaller e és appellat mossén Berenguer Mercader, menor de dies, e és fet major de XX anys e àbil de fer e contractat tot o que major de XX anys pot e deu fer, e axí appar per sentència». ${ }^{14} \mathrm{Se}$ trata, obviamente, del mossén Berenguer Mercader, «menor de dies»-para evitar confundirlo con el batle general-, que Guia i Marín considera el más probable anfitrión de Corella y demás contertulios.

11 En su condición de tutor y curador, Joan Mercader, restituyó el censo a la viuda, «la honorable dona Na Isabel, muller del dit quondam mossén Pere Mercader», quien lo vendió y, tras pasar por varios propietarios, acabó en manos de Pere de Monblanch en 1440 (AMV, CC O-28, ff. 122v-125r; 1453, abril, 27). «Ysabel, uxor honorabilis Petri Mercader, militis quondam habit. Valentie [...] michi pertinent et expectant titulo venditionis facte simul cum aliis censualibus in solutum mee dotis, per honorabilem Iohannem Mercader, legum doctor, baiulum generalem regni Valentie, Berengarium Mercader, militem, eius filium, et Petrum alias Perot Mercader, domicellum, habitatores dicte civitatis, tutores et curatores testamentarii persone et bonorum Berengarii Mercader, pupilli, filii et heredis universalis bonorum omnium et iurium que quondam fuerunt honorabilis Petri Mercader, militis, habitatoris dicte civitatis, deffuncti, patris eius [...] de dictis tutela et cura ac hereditate dicti Berengarii Mercader, pupilli, constat ultimo testamento predicti honorabilis Petri Mercader, patris eius, acto Valentie quinta die madii anno a nativitate Domini millesimo CCCC $^{\circ}$ vicesimo quinto» (id., Protocols, Joan de Santfeliu, q-4, s. fol.: 1438, diciembre, 24).

12 AMV, CCe, I-53, f. 14v (1435, agosto, 26)

13 El 23 de diciembre del año anterior se pagaba «a ·N Berenguer Mercader, fill e hereu de l'honorable mossén Pere Mercader, cavaller, quondam», y en nombre suyo a sus tutores, «micer Johan Mercader, major de dies, doctor en leys, mossén Berenguer Mercader e mossén Perot Mercader, cavallers» un censo de su propiedad. El 11 de febrero de 1441, también cobraban el censo los tutores, si bien a él se le cita como «l'honorable mossén Berenguer Mercader, ja fet cavaller, fill e hereu de l'honorable mossén Pere Mercader, cavaller, quondam» (AMV, CCe I-57, ff. 82r y 100r).

14 AMV, CC O-24, f. 57v-60r; y Protocols, Jaume Ximeno, 8-3, ff. 99v-100r (1471, mayo, 30).

SCRIPTA, Revista internacional de literatura i cultura medieval i moderna, núm. 14 / desembre 2019 / pp. 1 - 33 ISSN: 2340-4841 ·doi:10.7203/SCRIPTA.14.16357 
Hay noticia documental precisa, pues, de su filiación ${ }^{15}$ y de su edad. ${ }^{16}$ Nacido hacia 1421 , tendría 39 años en 1460, fecha en que el joven Corella cumpliría los 25 en la «vespra de la festa de sant Miquel» (Chiner Gimeno: 2013: 133). Es evidente, por tanto, que ni tenían la misma edad ni pertenecían a la misma generación. Lo que obliga a revisar la interpretación de la expresión «de vida e entendre conformes», argumento empleado para descartar al prócer. Si en 1460, según Guia, el viejo batle Mercader, y «una jove promesa de la teologia i la literatura, Joan Roís de Corella, de menys de vint-i-cinc anys», no podían ser personas de vida e entendre conformes, tampoco podrían serlo éste último y mossén Berenguer, menor de dies, distantes casi tres lustros en edad. Sin olvidar, por otro lado -y sobre todo-, que el autor sitúa la realización del Parlament, en la década de los ochenta. Pues bien, en 1480, antes de que comenzara el decenio, ni Corella, que tendría entonces 45 años, ni su amigo Berenguer, con 59, podrían haber tenido como contertulio a don Joan de Pròxita, uno de los participantes, puesto que éste llevaba cuatro años sin vida. Había fallecido el 10 de agosto de 1476, según exacta noticia del dietarista Miralles (Rodrigo Lizondo 2011: 443 y 445).

\section{La expresión «en vida e entendre conformes»}

A la vista de los datos biográficos, es insostenible la idea de la edad pareja de los contertulios que ha dado pie a presentar el Parlament como una reunión literaria de camaradas de la misma generación -y a negar que el batle general Berenguer Mercader fuese uno de ellos-, basada en una expresión que «suggereix que devien ser d'edat aproximada» (Ferrando Francés 2013: 639); «en vida e entendre conformes». A propósito del sintagma, es obligado hacer dos precisiones. En primer lugar, que la frase completa en que se encuentra, dice: «E tots, ab alegre concòrdia, de una veu deyen que altre delit, sens mescla de enuig, en aquest món attényer no ‘s dexa, sinó comunicar ab virtuoses

15 Abel Soler lo llama erróneamente «Berenguer Mercader i Soler» por creerlo hijo de Joana Soler. Sus progenitores fueron Pere Mercader, hijo de la citada Joana de Soler -era su abuela, por tanto- y de Isabel de Siscar, hija de mossén Pere de Siscar: «Pagats als honorables Na Isabel, muller de l’honorable mossén Pere Mercader, cavaller, quondam, habitador de la dita ciutat, e a mossén Berenguer Mercader, menor de dies, cavaller, fill dels dits conjuges e hereu del dit honorable mossén Pere Mercader, pare seu [...] originalment carregats sobre la dita universitat a la honorable dona Na Eyrovís, muller de l'honorable mossén Pere de Siscar, cavaller, habitador de la dita ciutat [...] Enaprés, la dita honorable dona $\mathrm{Na}$ Eyrovís féu regonexença del dit censal al dit honorable mossén Pere de Siscar, cavaller, marit seu [...] Lo dit honorable mossén Pere de Siscar, col locant en matrimoni la dita honorable dona Na Isabel, filla sua, ab lo dit honorable mossén Pere Mercader, constituí a aquell en la dot de aquella [...] Lo dit mossén Pere Mercader és mort e ab lo dit seu testament instituí hereu seu lo dit honorable mossén Berenguer Mercader, fill seu [...] Derrerament, l'onorable micer Johan Mercader, doctor en leys, batle general de regne de València, hu dels tudors e curadors al dit mossén Berenguer Mercader per lo dit pare seu en lo dit seu testament assignats, restituí a la dita Na Isabel los dits D sous censals» (AMV, CC J-67, ff. 17v-18r; 1454, enero, 14). También: ibid. J-66, f. 32r (1453, abril, 27).

16 Hasta ahora sólo había vaga sospecha de que «devia tenir uns quants anys més que Corella» (Ferrando Francés 2013: 640).

SCRIPTA, Revista internacional de literatura i cultura medieval i moderna, núm. 14 / desembre 2019 / pp. 1 - 33 ISSN: 2340-4841 $\cdot$ doi:10.7203/SCRIPTA.14.16357 
Agustín Rubio Vela. Sobre Berenguer Mercader, anfitrión del Parlament de Joan Roís de Corella, y demás contertulios

persones, en vida hi entendre conformes» (Martos 2001: 269).${ }^{17}$ En segundo lugar, que no es la única ocasión en que Corella alude elogiosamente al conjunto de los contertulios. A comienzos de la obra, con unas palabras -hasta ahora, a nuestro juicio, incomprensibles e incomprendidas-, anuncia: «recitaré un parlament que, pochs dies passats, entre alguns hòmens de stat sdevench, los noms dels quals no scriure, recitant l'alt e gentil stil de tant bé rahonades proses, seria a la sua inclita fama haver enveja e a vertadera amistat girar les spatles». ${ }^{18}$ Se completa así la alabanza de los cinco «hòmens d'estat», «virtuoses persones» con quienes el autor se siente unido por «vertadera amistat» y de cuya «únclita fama» se erige en portavoz.

¿Qué elementos de la expresión «en vida e entendre conformes» sugieren que las personas a que se refiere son individuos de similar edad? Desde luego, no el sustantivo verbal 'entendre', que reaparece en la obra: «amor té nostres penses entenebrades ab ofuscat entendre» (Martos 2001: 239). En el sintagma podría tener el significado de 'conocimiento', 'saber', palabra ésta con la que no es difícil encontrarlo emparejado en textos de la época: «notificam que, a tot nostre saber e entendre, proceir al present en missatgeria [...] seria capital prejuhí». ${ }^{19}$ El propio Corella, en el Parlament, lo utiliza así, en sentido negativo -falta de conocimientos, ignorancia-, en la expresión «la misèria del meu pobre desert entendre», que pone en boca de don Joan de Pròxita cuando, tras elogiarlo por «la sua condició affable», éste cede a los deseos de los contertulios «ab humilitat benigne» (Martos 2001: 270), remitiendo al tópico de modestia, tan frecuente en la época, por el que los autores pedían perdón por los posibles defectos de sus obras, atribuyéndolos humildemente a su propia «ignorància e imperfecció» (Rubio Vela 2017: 163-164). En cualquier caso, ni en ésta, ni en ninguna otra de las posibles acepciones del término 'entendre', se observa el menor matiz de edad generacional.

Lo mismo cabe decir del vocablo, 'vida'. Corella, al referirse a los participantes en el evento poético como personas «en vida [...] conformes», no da a 'vida' un sentido cronológico, sino moral, el mismo que se advierte cuando escribía en sus obras «virtuosa e benaventurada vida», «inquieta, viciosa e incriminada vida», «honesta vida» (Martos 2001: 210, 219, 245). En la Valencia de la época para definir o juzgar, positiva o negativamente, el perfil de un individuo, era habitual usar el vocablo en su acepción 'forma de vida' o 'modo de vida'. Las epístolas del siglo XV emanadas de la escribanía

17 Con una ligera variante en Miquel y Planas (1913: 261): «ab comunicaçio de virtuoses persones, en vida e entendre conformes».

18 Subrayado, puntuación y acentuación nuestros. En las ediciones de la obra, desde la de Miquel y Planas (1913: 233) hasta la de M. Gustà (1980: 45), la frase carece de sentido por faltar «no scriure» («los noms dels quals no scriure, recitant...»), sin duda por error del manuscrito que tomaron como base (Cancionero de Mayans). Sí figura en la de Martos (2001: 238), basada en el Códice de Cambridge, aunque el editor se equivoca al interpretar el infinitivo como futuro («los noms dels quals no scriuré; recitant...»), por lo que el texto sigue sin tener sentido; es evidente que Corella no sólo escribe los nombres (lo que contradice el «no scriuré»), sino que asegura que no hacerlo, «no scriure», sería reprochable para él, pues significaría «a la sua ínclita fama haver enveja e a vertadera amistat girar les spatles».

19 AMV, Lletres Missives [LM] 6, f. 30v (1398, julio, 24).

SCRIPTA, Revista internacional de literatura i cultura medieval i moderna, núm. 14 / desembre 2019 / pp. 1 - 33 ISSN: 2340-4841 · doi:10.7203/SCRIPTA.14.16357 
Agustín Rubio Vela. Sobre Berenguer Mercader, anfitrión del Parlament de Joan Roís de Corella, y demás contertulios

de los jurats de la ciudad pueden aportar numerosos ejemplos de ello. En septiembre de 1458, los ediles de la capital advertían al rey: «D’altra part, vós, senyor, creem vós hajau bé notícia de la condició, pràtica e vida del dit micer Pere Belluga». ${ }^{20}$ Pocas semanas antes, habían escrito al propio jurista en términos crudos, reprochándole «vostra acostumada manera de viure, la qual a Déu no plau res». ${ }^{21}$ Por el contrario, a Alfons de Borja, futuro papa Calixto III, atribuían tempranamente «lo do de sciència, la resplandor de loable vida, preclara e generosa conversació, e altres donaris de virtuts». ${ }^{22} \mathrm{El}$ también jurista misser Martí de Torres era objeto de alabanzas por «la honestat de la sua vida e clara sciència e altres moltes virtuts», por «les virtuts en què habunda lo dit micer Martí en vida, conversació e sciència». ${ }^{23}$ La palabra aflora con tanta reiteración en las misivas municipales de recomendación, que puede hablarse de un uso tópico en la descripción de perfiles humanos meritorios: «de bona e antiga natura e de clara fama, vida, sciència e virtuts dotat»; ${ }^{24}$ «és prohom e bon hom e de bona consciència, fama, vida e conversació»; ${ }^{25}$ «de bona fama, vida e conversació honesta»; ${ }^{26}$ «sa sufficiència, virtuts, vida e mèrits comendables»; ${ }^{27}$ «home dotat de virtuts, honestat e vida comendables»; ${ }^{28}$ «és persona simpla e de molt bona conversació e vida onesta»; ${ }^{29}$ «la sciència, vida e mèrits comendables»; ${ }^{30}$ «la vida, honestat e oracions». ${ }^{31}$

Vida -en el sentido de conducta-, virtud, fama. Corella emplea los tres conceptos en una de sus obras: «Ans desig lo meu mal, essent-los exemple, llur vida, en virtuts e honestat despesa, gloriosa eterna fama ls presente» (Martos 2001: 224). ${ }^{32}$ Son los mismos que afloran en sus frases de elogio dirigidas a los contertulios, «virtuoses persones, en vida e entendre conformes» $\mathrm{y}$ «de ínclita fama». No hay motivo real alguno para rechazar, basándose en ellas, la versión de que el batle general fuera uno

20 AMV, LM 23, f. 204r-v (1458, septiembre, 15).

21 AMV, LM 23, f. 196r (1458, agosto, 28).

22 AMV, LM 14, f. 138r-v (1419, agosto, 2).

23 AMV, LM 15, ff. 31r-32v (1421, enero, 24).

24 AMV, $L M$ 15, ff. 31r-32v (1421, enero, 24)

25 AMV, $L M$ 19, ff. 62r-63v (1438, juliol, 16).

26 AMV, LM 19, f. 155v (1439, noviembre, 25).

27 AMV, $L M$ 19, f. 200r-v (1440, mayo, 10).

28 AMV, MC 33, f. 279v (1447, marzo, 31).

29 AMV, LM 22, f. 4r (1453, mayo, 25).

30 AMV, LM 22, ff. 190v-191r (1455, septiembre, 20).

31 AMV, LM 26, f. 111v (1464, septiembre, 4).

32 López Quiles (2014: 412) comenta así la expresión: «gràcies al plany que hem llegit de Medea, les dones esmenen la seua conducta -'lur vida en virtuts e honestat despesa'-...»

SCRIPTA, Revista internacional de literatura i cultura medieval i moderna, núm. 14 / desembre 2019 / pp. 1 - 33 ISSN: 2340-4841 · doi:10.7203/SCRIPTA.14.16357 
Agustín Rubio Vela. Sobre Berenguer Mercader, anfitrión del Parlament de Joan Roís de Corella, y demás contertulios

de aquellos «hòmens d'estat» de gran fama que compartían conducta virtuosa y saberes. Porque nada sugiere que fueran personas de una misma edad o generación.

\title{
7. La casa del Parlament
}

En la Valencia de Corella, aludir a la casa de Berenguer Mercader había de evocar la vivienda de la calle dels Cavallers del que fue batle durante más de un cuarto de siglo, desde 1440 hasta 1467. Tan arraigada estaba la denominación, que aquella morada seguía siendo conocida en la ciudad como la «casa de mossén Berenguer Mercader» dos décadas después de su fallecimiento. Lo demuestran sendos pregones fechados en diciembre de 1489 y enero del siguiente, en los que los ediles señalaban el itinerario que había de seguir una procesión: «...per lo carrer dels Cavallers fins casa de mossén Berenguer Mercader, e de aquí girarà a mà esquerra e entrarà en lo monestir de menoretes de sancta Clara e de sancta Elisabet...»; «...per lo carrer dels Cavallers fins a la casa de mossén Berenguer Mercader, e girarà a Sent Nicholau...»». ${ }^{33}$

Estos datos documentales, que apuntalan la versión clásica de que el Berenguer Mercader del Parlament de Corella era el batle general y su casa de la calle dels Cavallers el lugar del evento (Rubio Vela 2013: 606-607), han sido desestimados, de manera implícita, por Abel Soler, cuando escribe:

\begin{abstract}
L'indret on té lloc l'exposició de faules exemplars dels 'antics' no sembla ser, en principi, un gran palau ni un alberg senyorial. És, simplement, la 'casa' d'un tal Berenguer Mercader. I, si aquest Berenguer Mercader haguera sigut l'ancià batle general del Regne de València, que moriria el 1471, no hem de dubtar gens que mossén Corella l'haguera tractat de 'molt noble e magnífich senyor' o de 'noble baró', igual que ho fa amb mossén Pròixida. Altrament, haguera incorregut en una inexplicable ofensa protocol lària. Sí: entre iguals -la resta són donzells i cavallers- era possible eludir els tractaments, però els qui posseïen privilegi de noblesa, com era el cas dels Pròixida o del batle Mercader, no podien permetre que no se'ls tractara amb els honors corresponents. I una persona tan ben formada i tan informada com era Corella no hauria incorregut mai en aquesta omissió». Algo más adelante, insiste: "La casa del batle general era coneguda popularment com 'la casa de mossén Berenguer Mercader'. Si el tractament de mossén per a un dels més nobles cavallers de València no era obviat per ningú, molt menys podria ser-ho per un escriptor com Roís de Corella, mal que fóra per cortesia i deferència; sobretot en un escrit on els ornaments són la norma i on Pròixida és sempre don. Roís de Corella ho tenia clar: aquella no era la casa del molt honorable mossén, sinó simplement 'la casa de Berenguer', un amic que no era cavaller (Soler 2014: 257 y 258).
\end{abstract}

En las frases anteriores, el autor desliza una serie de afirmaciones infundadas, aunque con apariencia de argumentación solvente, lo que obliga a analizarlas una a una, y de manera pormenorizada.

33 AMV, MC 45, ff. 353r-v (1489, diciembre, 27), y ff. 367v-368r (1490, enero, 20). 
Agustín Rubio Vela. Sobre Berenguer Mercader, anfitrión del Parlament de Joan Roís de Corella, y demás contertulios

Comenzaremos por «l'indret on té lloc» el cónclave poético, que «no sembla ser, en principi, un gran palau ni un alberg senyorial. És, simplement, la 'casa' d'un tal Berenguer Mercader». Un lector poco conocedor del mundo bajomedieval valenciano y de su terminología, ante la contraposición establecida por el autor entre, 'gran palau' o 'alberg senyorial', por un lado, y 'casa' por el otro, podría quedar convencido de que el Parlament [...] que [...] sdevench en casa de Berenguer Mercader tuvo como escenario una residencia modesta. Sería un error. Las grandes mansiones urbanas en que residían familias tan poderosas como los Castellví, los Fabra, los Carròs, los Pardo de la Casta, los Vilarrasa, recibían habitualmente el nombre de 'casa', incluido el palacio episcopal, llamado «casa del bisbe». ${ }^{34}$ Los itinerarios procesionales son bien elocuentes al respecto: «...e exirà per lo portal qui està envers casa d'En Berenguer Minguet e passarà per davant casa de mossén Johan Fabra e per casa d'En Pere Andreu e per casa de mossén Lluís de Castellví, e hirà per lo carrer de les Avellanes e per davant casa del bisbe e entrarà, per lo portal de la plaça de la Fruyta, en nostra dona Sancta Maria de la Seu»; ${ }^{35}$ «...e girarà per casa de mossén Pere Mascó, per davant casa d'En Loís Granollés, per la Çabateria e per la Freneria, e davant casa de mossén Pere Roïç, e, faent dreta via, per davant Sent Thomàs, per casa de mossén Carroç, per casa de mossén Perot Pardo e per casa de mossén Matheu Pujades, entrarà en la casa de la confraria de la dita verge Maria....»; ; «...irà per casa de mossén Loís de Soler, per lo carrer de mossén Ramon de Soler, per casa d'En Çedrelles, e entrarà en la sglésia de Sent Andreu [...] e per casa de mossén Vilarrasa, per casa del síndich, per la plaça de la Figuera, per lo carrer de les Avellanes, per casa del senyor cardenal e bisbe, tornarà en la dita Seu»». ${ }^{37}$

No era una excepción la casa del batle general del reino. En 1437, siéndolo aún misser Joan Mercader, padre de mossén Berenguer, leemos en una misiva: «...com de aquests affers se'n fossen ja justats dues vegades, ço és, en la Sala e en casa del batle general, on era stat delliberat fer lo dit jurament...». ${ }^{38}$ En 1453, cuando fue raptada una sobrina de Berenguer, en una carta de los jurats se lee: «Dimarts prop passat, hora de mija nit, mossén Pere d'Òdena, menor de dies, acompanyat ab altra certa gent, hora acaptada, vench a la casa de mossén Berenguer Mercader, batle general del regne de València, e d'allí, ab gran ultratge, ha treta e arapada Yolant, donzella, neboda del dit batle general, e filla de micer Johan Mercader, frare seu [...], cometent masa gran crim e delicte en la casa de un official tan preheminent del senyor rey e vostra com és lo dit batle general». ${ }^{39}$ En 1467, cuando la batlia general

34 AMV, MC 22, ff. 373r-374r (1405, diciembre, 22).

35 AMV, MC 29, ff. 43v-44r (1428, noviembre, 25).

36 AMV, MC 33, ff. 216v-217r (1446, agosto, 13).

37 AMV, MC 35, ff. 34v-35r (1450, agosto, 31).

38 AMV, MC 31, f. 138r (1437, octubre, 8).

39 AMV, $L M$ 21, f. 296r-v; 1453, abril, 13). El asunto se abordó en el Consell: «eren venguts a casa de mossén lo batle general [...] eren entrats en la dita casa de mossén lo batle [...] e li havien derrobat la casa, ço qui ls semblava mal fet e cosa de mal exemple haver fet hun tal insult, majorment en casa de hun tal official e tan preheminent com és lo dit

SCRIPTA, Revista internacional de literatura i cultura medieval i moderna, núm. 14 / desembre 2019 / pp. 1 - 33 ISSN: 2340-4841 $\cdot$ doi:10.7203/SCRIPTA.14.16357 
Agustín Rubio Vela. Sobre Berenguer Mercader, anfitrión del Parlament de Joan Roís de Corella, y demás contertulios

había pasado del padre al hijo, el síndic de la ciudad entregó un documento, «a l’honorable En Honorat Berenguer Mercader, batle general del regne de València, en la casa de son pare atrobat». ${ }^{40}$

La palabra 'casa', en sentido de vivienda, no puede interpretarse como residencia modesta contrapuesta a gran mansión. Cuando se afirma que la 'casa' del Berenguer Mercader del Parlament no es el «gran alberg senyorial» que el batle tenia «al carrer dels Cavallers de València», sino la 'casa' «d'un tal Berenguer Mercader», se hace a partir, no de un análisis documental, sino de un prejuicio: una 'casa' no podía ser un 'un gran alberg senyorial'. Un prejuicio erróneo, utilizado de manera insistente como prueba de que «el del Parlament és un dels tres Berenguers Mercader que convivien a València el 1460, però no és el batle general» (Soler 2014: 257 y 258). Abundante documentación coetánea, publicada con anterioridad al trabajo del citado autor (Rubio Vela 2013: 606-607), demuestra que el palacio señorial de la calle de Cavallers era siempre mencionado como 'casa'.

\section{Nobles y caballeros. Los tratamientos}

La otra razón que se arguye en contra de la versión clásica es de distinta naturaleza. Si la casa del Parlament fuese la de «l'ancià batle general del Regne de València», Corella, sin duda «l'haguera tractat de 'molt noble e magnífich senyor' o de 'noble baró', igual que ho fa amb mossén (sic) Pròixida. Altrament, haguera incorregut en una inexplicable ofensa protocol lària», puesto que «els qui posseïen privilegi de noblesa, com era el cas dels Pròixida o del batle Mercader, no podien permetre que no se'ls tractara amb els honors corresponents». Soler insiste en la nobleza del batle, «un dels més nobles cavallers de València», que Roís de Corella no podía obviar, «sobretot en un escrit on els ornaments són la norma i on Pròixida és sempre don». Pues bien, nos encontramos ante otro error sustancial: Berenguer Mercader, caballero, nunca perteneció a la nobleza, a diferencia de Joan de Pròxita - a quien en el Parlament jamás se alude como 'mossén'-, cuyo rango nobiliario, perfectamente documentado, venía de muy atrás.

Efectivamente, Berenguer nunca poseyó «privilegi de noblesa». Y nunca hubera podido ser tratadao, contrariamente a lo que cree Soler, de 'molt noble e magnífich senyor' o de 'noble baró'. Son muchas las misivas que le dirigieron los jurats de Valencia -éstas sí rigurosamente estrictas en lo que a rango, tratamiento y títulos se refiere- que lo demuestran. He aquí, como ejemplo, una fechada en 1463: "Al molt magníffich mossènyer e de gran saviesa mossén Berenguer Mercader, batle general del regne de València». ${ }^{41}$ Tres años más adelante, el último de su actividad al frente de la batlia general, el juramento de los nuevos jurats se hacía «en poder e mans del molt honorable mossén

batle general» (id., MC 35, ff. 252r-253v; 1453, abril, 12).

40 AMV, MC 38, f. 146(a)r (1467, septiembre, 12).

41 AMV, LM 25, f. 179r (1463, enero, 15).

SCRIPTA, Revista internacional de literatura i cultura medieval i moderna, núm. 14 / desembre 2019 / pp. 1 - 33 ISSN: 2340-4841 $\cdot$ doi:10.7203/SCRIPTA.14.16357 
Agustín Rubio Vela. Sobre Berenguer Mercader, anfitrión del Parlament de Joan Roís de Corella, y demás contertulios

Berenguer Mercader, conseller del molt alt senyor rey e per ell mateix senyor batle general del regne de València». ${ }^{42}$ En ninguno de los dos casos incurrían los ediles «en una inexplicable ofensa protocol lària», como el autor citado hubiera interpretado, puesto que el destinatario no poseía el «privilegi de noblesa» que arbitrariamente le atribuye, con la intención de equipararlo a don Joan de Pròxita, a cuyos antepasados sí se dirigían desde antiguo los jurats dándoles tratamiento de 'noble baró': «Al molt noble baró mossén Olfo de Pròxida, governador de la ciutat e regne de Mallorques». ${ }^{43}$

El error del autor radica en la confusión entre el concepto de 'noble' en sentido amplio, equivalente a persona del estamento militar, y el de 'noble' stricto sensu, esto es, la persona que tiene privilegio de nobleza. En sentido genérico se habla de nobleza o de pequeña nobeza en los estudios históricos, pero siempre de manera impropia, pues solamente una parte de los miembros del estamento militar eran nobles, calificados de nobles y tratados como nobles, como bien indica, para el caso valenciano, López Rodríguez (2005: 620-621). Aunque en múltiples ocasiones se empleen como sinónimos, 'noble' y 'cavaller' no eran lo mismo. Lo demuestra una simple mirada a los documentos de la época, donde se pueden localizar frases tan elocuentes como la siguiente: «...si serà noble hom, a noble hom, si serà cavaller, a cavaller, si serà ciutadà, a ciutadà.... ${ }^{44}$ Pues bien, los Pròxita eran nobles. Los Mercader no. Un acta de las cortesvalencianas lo pone de manifiesto con meridiana claridad en el caso, precisamente, de los dos individuos a que aquí nos referimos. El 15 de febrero de 1463, ambos fueron convocados a asistir, mediante cartas del monarca dirigidas, en estricto orden protocolario, primero a los nobles («Pro brachio nobilium») y luego a los caballeros que no lo eran («Pro brachio militari»). Entre aquéllos está la enviada «Al noble, magníffich e amat del senyor rey don Johan de Pròxita»; entre los segundos, la que se había de entregar «Al magníffich e amat del senyor rey mossén Berenguer Mercader, cavaller». ${ }^{45}$

No acaban aquí las afirmaciones infundadas con apariencia de argumentos serios. Subraya Soler el hecho de que en el Parlament no se le da a Berenguer Mercader el tratamiento de 'mossén'. Una señal, a su juicio, de que no podría ser el batle: «Si el tractament de mossén per a un dels més nobles cavallers de València no era obviat per ningú, molt menys podria ser-ho per un escriptor com Roís de Corella, mal que fóra per cortesia i deferència; sobretot en un escrit on els ornaments són la norma i on Pròixida és sempre don». La omisión del 'mossén' antepuesto al nombre del batle sería una falta de cortesía hacia éste, teniendo en cuenta que a Joan de Pròxita sí se le antepone el 'don', que «s'usava des de l'arribada dels Trastàmara al tron, per a distingir els nobles barons -aquells

42 AMV, MC 38, ff. 70(a)r-71(a)r (1466, mayo, 25).

43 AMV, $L M$ 17, f. 77r-v (1423, diciembre, 27).

44 AMV, Procesos de cortes, yy-12, f. 48v (1429, diciembre, 19).

45 AMV, Procesos de cortes, yy-20, ff. 7r-v, 10r y 13r. No hay duda de que se trata del anciano batle, pues su homónimo figura también, pero claramente diferenciado de aquél: «Al magníffich e amat del senyor rey mossén Berenguer Mercader, menor, cavaller» (ibid., ff. 10r).

SCRIPTA, Revista internacional de literatura i cultura medieval i moderna, núm. 14 / desembre 2019 / pp. 1 - 33 ISSN: 2340-4841 · doi:10.7203/SCRIPTA.14.16357 
Agustín Rubio Vela. Sobre Berenguer Mercader, anfitrión del Parlament de Joan Roís de Corella, y demás contertulios

que gaudien de privilegi de noblesa i importants estats senyorials- de la resta d'integrants del braç militar: els cavallers i donzells o generosos en general» (Soler 2014: 273) ${ }^{46}$

De nuevo nos encontramos ante una suposición errónea. En primer lugar, porque el 'don' no era un tratamiento distintivo de los nobles frente al resto de los integrantes del estamento militar, sino un título distintivo del que podían hacer ostentación sólo algunos nobles, muy pocos, de ciertos linajes -. independientemente de que fueran o no caballeros-, por concesión real. El de los Pròxita constituye un ejemplo perfecto.

Es sabido que la familia pertenecía a la nobleza valenciana desde muy antiguo (López Rodríguez 2005: 67-70, 87, 89...) Sin embargo, sus miembros no tuvieron título de 'don' hasta la segunda mitad del siglo XV. No lo tuvo el que fuera gobernador de Orihuela y de Mallorca, que siempre figura como «mossén Olfo de Pròxida» (véase nota núm. 44 y Rubio Vela 1998: 128 y 135). Tampoco Joan, su hermano y heredero, ${ }^{47}$ a quien se le cita como «mossén Johan de Pròxida» en 1431 y 1434 (Gual Camarena 1951: 108; Pérez Pérez 1971: 128 y 129), así como en 1437 y $1438 .{ }^{48}$ En 1457, su viuda, era «la molt noble e magnífica senyora dona Isabel de Proxida, muller del molt noble e magnífich mossén Joan de Proxida, quondam cavaller, senyora dels castells e llochs de Palma e Ador dins regne de Valencia situats». ${ }^{49}$ Su hijo primogénito, Nicolau, al que nombró heredero (Rius Serra 1948-1958: I, 421), aparece mencionado como «lo noble En Nicolau de Pròxita» en 1450 (Villalmanzo 1995: 518), 1451, 1452 y $1453 .{ }^{50}$ En la última fecha, los jurats aludían a él y a su hermano Joan como «En Nicholau de Pròxita e son germà, Johanot de Pròxita» (Rubio Vela 1998: 128 y 308). Estaban involucrados en una guerra particular: «lo debat e discràsia que era stada suscitada entre los nobles mossén Guillem Ramon Centelles e En Nicholau de Pròxita, e lurs germans». ${ }^{51}$ Obviamente, no eran aún caballeros. Tampoco lo

46 Con anterioridad, Ferrando Francés (2013: 641) también había observado que en los manuscritos conservados no se antepone el 'mossén' a ninguno de los contertulios y «en canvi, Joan de Pròixita hi és presentat com a lo noble i amb el títol de don».

47 «Nos, Iohannes de Pròxita, miles heresque universalis bonorum omnium que quondam fuerunt nobilis Olfoni de Pròxita, militis, consiliarii et camarlengii illustrissime domine regine Elionoris Aragonum, quondam, fratris mei...» Lo fue en virtud del testamento de Olf, realizado el 28 de abril de 1422 y publicado el 5 de marzo de 1425 (AMV, Protocols, Jaume Beneyto, r-1, s. fol.; 1425, octubre, 26. Tarazona).

48 AMV, Procesos de cortes, yy-15, ff. 165r (1437, julio, 8) y 248v (1438, abril, 28).

49 Villalmanzo, Ausias March. Colección documental, p. 367.

50 «Sobre 1 fet del vi que lo noble En Nicholau de Pròxita fahia portar d'Almenara...» (AMV, MC 35, f. 133r; 1451, octubre, 8); «Presents testimonis foren a les dites coses, los noble e honorables En Nicholau de Pròxita...» (f. 147v; 1451, diciembre, 25; f. 215v; 1452, septiembre, 29); «a grans prechs e instància del noble En Nicholau de Pròxita» (f. 221r; 1452, noviembre, 10); «...per lo viatge per aquell, de nostra ordinació, fet ·Alcocer, al noble En Nicholau de Pròxita» (f. 246v; 1453, marzo, 23).

51 AMV, MC 35, ff. 288r-289v (1453, agosto, 7).

SCRIPTA, Revista internacional de literatura i cultura medieval i moderna, núm. 14 / desembre 2019 / pp. 1 - 33 ISSN: 2340-4841 · doi:10.7203/SCRIPTA.14.16357 
Agustín Rubio Vela. Sobre Berenguer Mercader, anfitrión del Parlament de Joan Roís de Corella, y demás contertulios

era en 1457 otro hermano menor, Tomàs de Pròxita, a quien se le cita en 1457 como noble, pero sin la condición de miles. ${ }^{52}$

Sin embargo, en 1460, Joan ya es citado como caballero y con el 'don' antepuesto: «...davant la presència dels nobles e magnífichs don Johan de Pròxita e mossén Arnau Guillem de Bellera, cavallers...»(Villalmanzo 1999: 418). Y en 1463, en las misivas de convocatoria a las cortes valencianas, los Pròxita figuran con el «don»: "Al noble magníffich e amat del senyor rey don Nicholau de Pròxita. Al noble magníffich e amat del senyor rey don Johan de Pròxita. Al noble magníffich e amat del senyor rey don Thomàs de Pròxita. Al noble magníffich e amat del senyor rey don Elfo de Pròxita». ${ }^{53}$ Nacidos nobles, pero sin el 'don' antepuesto al nombre de pila, fueron los primeros del linaje en poder exhibirlo.

El título honorífico parece coincidir con un viaje a la corte italiana de Alfonso el Magnánimo que hicieron los dos primeros en 1458, último año de su reinado. El 4 de marzo de dicho año, en Nápoles, «Nicolaus de Pròxita, miles, baronus ac dominus baroniarum de Almenara, de Lucent et de Alcocer, serenissimi domini regis consiliarius et camarlengus», nombraba procuradores suyos en Valencia, mientras durase su ausencia, a su madre, Isabel de Pròxita, y a sus hermanos, Ladrón de Ladrón, vizconde de Manzanera, y Tomàs de Pròxita, bachiller en decretos. ${ }^{54} \mathrm{Y}$ allí, en un documento notarial fechado en Capua el 25 de julio -un mes después del óbito del monarca-, tras el texto de una letra de cambio firmada por Joan de Pròxita («ego, Ioannes de Pròxita, miles, oriundus e regno Valentie, in civitate Capue impresentiarum degens»), dirigida al notario de Valencia Francesc Rubert, fechada en Nápoles el 3 de julio de 1458, encontramos por primera vez su nombre precedido del 'don': «Yo, Jacme Calatayú, són tengut en lo present cambi com a principal prenedor, e so content los dits CL ducats sien donats al dit don Joan de Pròxida... ${ }^{55}$ El mismo día 3 de julio, tras la copia de otra «quarta de cambi», nuevamente aparece el 'don': «...sien donats al dit don Joan de Pròxita... ${ }^{56} \mathrm{~A}$ finales de agosto, Joan se encontraba en Roma, donde se le cita como «nobilem et magnificum virum dominum Johanem de Proxita, militem»(Cassanyes Roig 2018: 146-147). En adelante, el 'don' antecederá de manera sistemática a su nombre (Villalmanzo 1995: 543 y 544; Rodrigo Lizondo 2011: 274 y 296).

52 «Axí per los nobles mossén Pere Pardo, cavaller e En Thomàs de Pròxida, e per mosén Bernat Johan, cavaller, e En Johan de Nàthera, generós, elets e deputats per lo stament militar del regne de València...» (AMV, LM 23, f. 110r-v; 1457, julio, 11).

53 AMV, Procesos de cortes, yy-20, ff. 7r-v.

54 AMV, Protocols, Jaume Ximeno, s-5, s. fol.; id., Protocols, Jaume Ximeno 7-3, f. 111 r-v.

55 AMV, Protocols, Jaume Ximeno, s-5, s. fol. (1458, julio, 25).

56 AMV, Protocols, Jaume Ximeno 7-3, f. 123r-v (1458, julio, 25).

SCRIPTA, Revista internacional de literatura i cultura medieval i moderna, núm. 14 / desembre 2019 / pp. 1 - 33 ISSN: 2340-4841 $\cdot$ doi:10.7203/SCRIPTA.14.16357 
Agustín Rubio Vela. Sobre Berenguer Mercader, anfitrión del Parlament de Joan Roís de Corella, y demás contertulios

El 'don' no anulaba al 'mossén' caballeresco, sino que lo desplazaba por su superior rango protocolario. ${ }^{57}$ Eran «ornaments» de diferente naturaleza. El primero, un título que indicaba, dentro de la nobleza, mayor distinción, estaba inseparablemente unido al nombre de pila de quienes podían exhibirlo. De ahí que, desde el momento en que le fue concedido a los Pròxita -tal vez una señal de afecto o gratitud del rey Alfonso-, Joan pasara a ser el «noble baró i cavaller don Joan de Pròixida». El 'mossén', en cambio, no era un título, sino un tratamiento al que tenían derecho quienes alcanzaban la condición de caballero. $\mathrm{Ni}$ indicaba nobleza ni era hereditario. Al igual que el 'En', podía preceder tanto al nombre de pila como al apellido. No así el 'don', que sólo antecede al primero. De ahí que sea posible encontrar documentos en los que aparezca un 'mossén' Pròxita, pero nunca un 'don' Pròxita.

Volvemos al caso que nos ocupa. Es obligado insistir en que, en el Parlament están ausentes tanto el 'En', propio de los donceles, como el 'mossén' caballeresco, ${ }^{58}$ por lo que ninguno de los contertulios figura con su nombre precedido de tales tratamientos. Ni siquiera Joan Roís de Corella, que era caballero, se aplica el 'mossén' a sí mismo: un dato que ha de tenerse en cuenta, y que vuelve a indicar que el 'mossén' y el 'don' nobiliario de los Pròxita no son comparables.

\section{La relevancia del batle}

El último día de diciembre de 1439, tras haber resignado misser Joan Mercader la batlia general en favor de su hijo Berenguer, comenzó a ejercer el cargo de batle en nombre de éste, ausente entonces, otro miembro de la familia: Perot Mercader. ${ }^{59}$ Duró un año su regencia. El 27 de enero de 1441, el titular, vuelto de la corte del rey Alfonso, tomaba las riendas: «l'onorable mossén Berenguer Mercader, cavaller, habitador de la ciutat de València, cambrer e conseller del molt alt senyor rey e batle general per lo dit senyor de la dita ciutat e de son regne, constituït personalment en la Seu de València, dita missa, davant l'altar major en presència dels honorables jurats de la dita ciutat e de gran multitud de poble e de mi, Jacme Beneyto, notari, scrivà dels honorables jurats e consell de la ciutat dessús dita, jurà sobre hun missal posat en lo dit altar major a Déu e als sancts Evangelis de aquell, per la sua mà dreta corporalment toquats, servar furs e privilegis, usos, bones costumes

57 Al hijo de Nicolau de Pròxida, en el Dietari del capellà, se le llama «mossén Francesch Johan de Pròxita» y «don Francesch Johan de Pròxita» (Rodrigo Lizondo 2011: 446 y 448).

58 Algo que no tiene en cuenta Ferrando Francés cuando escribe: «Si el Parlament s’hagués produit després de setembre del 1461, Corella difícilment hauria deixat d'atorgar-li [a Guillem Ramon] el tractament de cavaller» (2013: 641 y 642).

59 «l'onorable mossén Perot Mercader, cavaller, procurador assert de l'honorable mossén Berenguer Mercader, cavaller, novament proveït per lo senyor rey en batle general del regne de València per resignació feta per lo honorable micer Johan Mercader, pare seu, del dit offici [...] jurà sobre hun missal posat en lo dit altar major a Déu e als sancts Evangelis de aquell per la sua man dreta corporalment toquats, en nom del dit honorable mossén Berenguer Mercader batle general principal seu, servar furs e privilegis de la dita ciutat e regne de València» (AMV, MC 32 (fol. a), f. 137r-v). 
Agustín Rubio Vela. Sobre Berenguer Mercader, anfitrión del Parlament de Joan Roís de Corella, y demás contertulios

e libertats de la dita ciutat e regne de València»». ${ }^{60}$ Con esta ceremonia, tras años en la corte del Magnánimo, donde encontramos a Berenguer en 1422 y 1437 como «cambrer e conseller» del rey (Rubio Vela 2000: 27, 112, 133), daba comienzo su larga etapa al frente de una institución que conocía bien, pues consta que con anterioridad había sustituido ocasionalmente a su padre. ${ }^{61}$

El oficio de batle general que ejercería Berenguer Mercader en adelante, lo convertía en el máximo representante institucional de la Corona en la capital del reino, donde tenía su sede permanente. Es preciso subrayar la relevancia de este cargo, sobre todo teniendo en cuenta que abundan las referencias equivocadas. ${ }^{62}$ La persona que lo ostentaba había de gozar, obviamente, de la confianza plena del rey, por cuyos intereses económicos y políticos había de velar. De ello dan cuenta las frecuentes intervenciones de Berenguer Mercader en la sede del gobierno municipal para solicitar favores en nombre del monarca, siempre consignadas en las actas. Algunas de estas intervenciones resultan particularmente interesantes por cuanto indican una voluntad de estilo en su oratoria. En octubre de 1444, la belleza de sus palabras en una comparecencia ante el Consell de la ciudad mereció estos elogios: «E finalment, premeses al dit honorable consell, elegantment, abta e discreta, moltes altres bones e notables paraules persuasives, exortatives e altres fahents al propòsit de la matèria, lo dit honorable batle general, de part de la dita senyora reyna, ab tota devoció e affecció, pregà lo dit honorable consell que.... ${ }^{63}$ Dos años después, en el mismo lugar, tras la lectura de una credencial del rey, el escrivà de la Sala anotaba: «E, lesta la dita letra, lo dit batle general, en vigor de la creença per lo dit senyor a aquell acomanada en la dita letra, dix e explicà molt abtament e discreta que lo dit senyor.... ${ }^{64}$ La elocuencia de mossén Berenguer volvió a suscitar calificativos encomiásticos a principios de 1454, cuando, en nombre de la reina lugarteniente y de Juan de Navarra, futuro Juan II, intervino ante el gobierno municipal: «E, aquelles lestes e publicades, de continent, lo dit honorable batle general, molt elegantment e ab paraules decents e ornades, dix e proposà al dit honorable consell...». ${ }^{65}$

60 AMV, MC 32 (fol. a), f. 232r (1441, enero, 27).

61 El 19 de mayo de 1431, fue él quien eligió a los jurats y presidió al día siguiente el acto de juramento en la catedral: «e aquí matex l'onorable mossén Berenguer Mercader, cavaller, conseller del molt alt senyor rey, en loch de l'honorable micer Johan Mercader, batle general de regne de València, donà e publicà en ple consell en jurats...» (AMV, MC 29, ff. 125v-127r). El 3 de mayo de 1433, igualmente: «l'honorable mossén Berenguer Mercader, cavaller, en loch de l'honorable micer Johan Mercader, batle general de regne de València, donà e publicà en ple consell en jurats...» (AMV, MC 30, ff. 69r-v y 71r).

62 Desde que Riquer aludiera a Berenguer Mercader como «governador general de València» (1980: III, 315), la confusión ha pasado a estudios y ediciones de la obra de Corella: Gustà 1980: 13, Mérida Jiménez 1999: 304; Martos 2001: 114, que lo hace «lloctinent a València».

63 Archivo Municipal de Valencia [AMV], Manuals de Consells [MC] 33, ff. 47v-49r (1444, octubre, 27).

64 AMV, MC 33, f. 191r (1446, mayo, 27).

65 AMV, MC 35, ff. 331r-332v (1454, enero, 21).

SCRIPTA, Revista internacional de literatura i cultura medieval i moderna, núm. 14 / desembre 2019 / pp. 1 - 33 ISSN: 2340-4841 · doi:10.7203/SCRIPTA.14.16357 
Agustín Rubio Vela. Sobre Berenguer Mercader, anfitrión del Parlament de Joan Roís de Corella, y demás contertulios

Por otro lado, es preciso tener en cuenta que, en la ciudad Valencia, correspondía al batle -en ausencia del soberano o de su lugarteniente, que era lo habitual- elegir personalmente cada año, de entre los candidatos propuestos por los distritos parroquiales de la ciudad, a los que habían estar al frente de las tres principales instituciones municipales de gobierno: los jurats, ${ }^{66}$ el mostassaf ${ }^{67}$ y los justícies. ${ }^{6}{ }^{8}$ Desde el momento de la llegada de Berenguer a la batlia, las actas municipales dan cuenta de ello: «l'onorable mossén Berenguer Mercader, conseller e cambrer del senyor rey, e per lo dit senyor batle general del regne de València, qui aquí era present [...] donà e publicà en plen consell, en jurats ciutadans a hun any propvinent los honorables [...]; lo dit honorable batle general donà e publicà al dit consell, en jurats cavallers de la dita ciutat al dit hun any, los honorables.... ${ }^{69}$

La superioridad del batle general como autoridad no sólo se mostraba dentro de los muros de la casa del Consell esas tres veces al año en que decidía los nombramientos. Su notoriedad y poder se exhibían al día siguiente de las designaciones en el altar mayor de la catedral valentina, donde, en presencia de una multitud, presidía la ceremonia solemne de los juramentos, tomados por él, de los jurats, del mostassaf y de los justícies. En las actas municipales quedaban registrados esos actos, que se celebraban cada año el domingo de Quinquagésima, el 29 de septiembre (san Miguel) y el 25 de diciembre (Navidad), siempre en parecidos términos: «Constituït en la ecclésia de nostra dona Sancta Maria de la Seu de la dita ciutat, ço és, davant l'altar major de aquella, jurà per nostre senyor Déu e per la creu e per los Evangelis de Aquell, sancts, per ell corporalment tocats, en poder

66 «En la forma sobredita fo proceït a elecció de jurats cavallers o generosos, e caygueren o vengueren en la sort d'aquesta elecció les parròquies de Sent Lorenç, e de Sent Stheve. E, feta semblant publicació de les X parròquies e de les dessús nomenades dues, tantost e aquí mateix ubertes los dos redolins e vists los noms de les cèdules d'aquells, lo dit batle general donà e publicà al dit consell, en jurats cavallers o generosos de la dita ciutat al dit I any, los honorables mossén Matheu Lançol e En Johan de Claramunt, olim Vilarnau, habitadors de la dita ciutat» (AMV, MC 29, ff. 90v-91r; 1429, mayo, 14).

67 En 1435, en la «elecció de mostaçaf, vengueren en la sort las parroquias de Santa Maria, Sant. Andreu y Santa Caterina [...] E encontinent e aquí mateix, l’onorable micer Johan Mercader, batle general de regne de València, pres los dits redolins e, uberts aquells, donà e publicà al dit consell per mostaçaff de la dita ciutat, a hun any propvinent, l'onorable En Loís Garcia, ciutadà de la dita ciutat, dat e nomenat per la dita parròquia de Senta Maria» (AMV, MC 31, f. 39v).

68 La elección del justícia civill en 1434: «E encontinent lo dit honorable consell, sens divertir a altres affers, procehí a fer elecció de justícia civil per mort de l’honorable En Johan Gamiça, enaxí que, fets dotze redolins, segons lo nombre de les parròquies dins mur de la ciutat dessús dita, levats o preses del baçí ple d'aygua tres dels dits redolins per mà d'un inffant e aquells meses en mà de l'honorable micer Johan Mercader, doctor en leys e batle general de regne de València, e uberts singularment los romanents nou redolins e les parròquies d'aquells dades e publicades per fora de sort d'aquesta elecció, publicades axí matex les tres parròquies dels primers tres redolins com a romanents en la dita sort, ço és, de Sancta Maria, de Sent Martí e de Sent Lorenç, e encontinent e aquí mateix lo dit honorable micer Johan Mercader, presents los honorables jurats e en presència de tot lo consell, donà e publicà per justícia civil l'onorable en Manuel Suau, ciutadan de la dita ciutat, dat e nomenat a aquest offici per la parròquia de Sancta Maria» (AMV, MC 30 f. 123v; 1434, febrero, 23).

69 AMV, MC 32, ff. 259(a)v-260(a)v (1441, junio, 3). Como en el original hay dos foliaciones sucesivas, diferenciamos la primera de la segunda indicando, respectivamente (a) o (b) tras el folio.

SCRIPTA, Revista internacional de literatura i cultura medieval i moderna, núm. 14 / desembre 2019 / pp. 1 - 33 ISSN: 2340-4841 ·doi:10.7203/SCRIPTA.14.16357 
Agustín Rubio Vela. Sobre Berenguer Mercader, anfitrión del Parlament de Joan Roís de Corella, y demás contertulios

de l'honorable mossén Berenguer Mercader, cavaller, conseller del molt alt senyor rey e batle general del regne de València, en presència dels honorables jurats e de gran multitud de poble de la dita ciutat». ${ }^{70}$

\section{Influencia política y favores familiares}

La influencia y capacidad del batle Berenguer Mercader en el terreno político explica la reiteración con que miembros de su familia, de la que él era cabeza, fueron designados para ocupar cargos de relieve en el gobierno de la ciudad de Valencia. Ya en 1440, cuando Perot Mercader actuó como regente suyo, ${ }^{71}$ éste nombró jurat a Galceran Mercader. ${ }^{72}$ A partir de la llegada de Berenguer, los nombramientos se suceden: en 1442, mossén Guillem Mercader era designado jurat, ${ }^{73}$ en septiembre de 1444, Galceran Mercader conseller generós, era elegido mostassaf $f^{74}$ el 25 de diciembre, mossén Guillem Mercader juraba el cargo de justícia civil $7^{75}$ dos años más tarde, el 4 de junio de 1446, era de nuevo jurat «En Galceran Mercader, generós»; ${ }^{76}$ en 1447, éste último figura como conseller generós y misser Joan Mercader, hermano del batle, como conseller por los juristas. ${ }^{77}$ Galcerán volvía a ejercer los oficios de justicia criminal en $1448^{78}$ y de jurat en $1449 ; ;^{79}$ en mayo de 1450 era nuevamente conseller

70 AMV, MC 35, f. 130r (1451, septiembre, 29).

71 «...constituït personalment lo honorable mossén Perot Mercader, cavaller, habitador de la ciutat de València, regent lo offici de batle general del regne de València per lo honorable mossèn Berenguer Mercader, cavaller, habitador de la dita ciutat, batle general del dit regne, per resignació feta per lo honorable micer Johan Mercader, major de dies, olim batle general del dit regne...» (AMV, MC 32, f. 152(a)r-v; 1440, marzo, 14).

72 «lo dit honorable mossén Perot Mercader, regent la dita batlia, donà e publicà al dit consell en jurats cavaller e generós al dit hun any los honorables mossén Galceran de Montsoriu, cavaller, e En Galceran Mercader, generós, habitadors de la dita ciutat» (AMV, MC 32 (fol. a), ff. 170(a)v-171r; 1440, mayo, 14).

73 AMV, MC 32 (fol. b), f. 59r (1442, mayo, 19).

74 AMV, MC 33, ff. 5v (1444, junio, 5), y 33v (1444, septiembre, 28)

75 AMV, MC 33, f. 73r (1444, diciembre, 22).

76 AMV, MC 33, f. 197v.

77 AMV, MC 34, ff. 6r-7r (1447, mayo, 27). En septiembre del año anterior, este último, el jurista misser Joan Mercader, ejercía como regente el cargo de batle, por ausencia de su hermano. El nuevo mostassaf juraba «en poder de l'honorable micer Johan Mercader, doctor en leys, regent l'offici de batle general, per absència de l'honorable mossén Berenguer Mercader, cavaller, conseller del molt alt senyor rey e batle general» (AMV, MC 33, f. 225r).

78 Ordenaba el gobierno municipal el último día de enero de 1448 «que a l’honorable En Galceran Mercader, justícia criminal de la dita ciutat, de les peccúnies comunes de aquella fossen liurades a bestreta trenta lliures necessàries per alguns affers de la dita ciutat, assats arduus» (AMV, MC 34, ff. 51v-52r).

79 AMV, MC 34, ff. 198v-200r (1449, mayo, 31).

SCRIPTA, Revista internacional de literatura i cultura medieval i moderna, núm. 14 / desembre 2019 / pp. 1 - 33 ISSN: 2340-4841 · doi:10.7203/SCRIPTA.14.16357 
Agustín Rubio Vela. Sobre Berenguer Mercader, anfitrión del Parlament de Joan Roís de Corella, y demás contertulios

generós. ${ }^{80}$ En noviembre marchó a Nápoles,${ }^{81}$ donde permaneció hasta el fallecimiento de Alfonso el Magnánimo. En 1459, tras su retorno, volveremos a encontrarlo en cargo de jurat. ${ }^{82}$ Pocos meses después, siéndolo aún, murió. ${ }^{83}$

Fue durante los años de ausencia de Galceran cuando comenzó a ocupar oficios municipales el sobrino homónimo del batle, obviamente por designación de éste. Conseller generós en 1449, ${ }^{84}$ el 28 de septiembre del año siguiente, era nombrado mostassaf «l'honorable mossén Berenguer Mercader, menor de dies, cavaller, habitador de la dita ciutat, dat e nomenat per la dita parròquia de Sent Berthomeu», que al día siguiente haría su juramento solemne en la catedral, «en poder de l'honorable mossén Berenguer Mercader, cavaller, conseller del molt alt senyor rey e batle general del regne de València». ${ }^{85}$ En 1455 era nombrado jurat y realizaba al día siguiente en la catedral, ante su tío, el juramento solemne. ${ }^{86}$ En 1456, como edil saliente, era conseller generós. ${ }^{87}$ En 1458 volvía a repetirse la elección: «E, feta semblant publicació de les deu parròquies e de les dessús nomenades dues, tantost e aquí mateix uberts los dos redolins e vist los noms de les cèdules de aquells, lo dit honorable batle general donà e publicà al dit consell, en jurats generosos de la dita ciutat al dit hun any, los honorables mossén Johan Vives e mossén Berenguer Mercader, habitadors de la dita ciutat». ${ }^{88}$ En 1459 era de nuevo conseller generós $;{ }^{89}$ en 1461, jurat, ${ }^{90}$ en 1462 , siendo conseller generós, ${ }^{91}$ era designado mostassaf, siempre por decisión del batle: «Encontinent, e aquí mateix, l'onorable mossén Berenguer Mercader, batle general del regne de València, pres

$80 \mathrm{AMV}, M C$ 35, f. 7 r (1450, mayo, 27).

81 «...per dret de sagell de certes provisions del senyor rey que l’honorable En Galceran Mercader, generós, qui ‘s troba en Nàpols, ha obtengut del dit senyor e tramés als dits honorables jurats en favor de la dita ciutał» (AMV, MC 35, f. $52 \mathrm{v} 1450$, noviembre 14).

82 AMV, MC 36, f. 167(b)v-168(b)r (1459, mayo, 12).

83 «a N Pere Ferrer, texidor de draps d'or [...] li han comprat hun drap d'or vermell appellat ricamat, de tretze palms de larch per obs de la sopoltura de l'honorable mossén Galceran Mercader, quondam, cavaller, qui era jurat de la dita ciutat [...], segons en semblants sopoltures dels qui moren jurats és acostumat» (AMV, MC 36, f. 198(b)r; 1459, noviembre, 24).

84 AMV, MC 34, 206v-207r (1449, junio, 7).

85 AMV, MC 35, f.41v (1450, mayo, 27).

86 AMV, MC 35, f. 464r (1455, mayo, 24); y MC 36, ff. 1(a)r-2(a)v.

87 AMV, MC 36, f. 83(a)v (1456, mayo, 21).

88 AMV, MC 36, f. 79(b)r (1458, mayo, 20).

89 AMV, MC 36, f. 173(b)v (1459, mayo, 18).

90 AMV, MC 37, f. 76(a)v (1461, mayo, 23).

91 AMV, MC 37, f. 4(b)r (1462, junio, 12).

SCRIPTA, Revista internacional de literatura i cultura medieval i moderna, núm. 14 / desembre 2019 / pp. 1 - 33 ISSN: 2340-4841 · doi:10.7203/SCRIPTA.14.16357 
los tres redolins e, uberts aquells, donà e publicà al dit consell per mostaçaf de la dita ciutat, a hun any propvinent, lo honorable mossén Berenguer Mercader, cavaller, habitador de la dita ciutat, dat e nomenat per la dita parròquia de Sent Martí». ${ }^{92}$ En 1464 repetía como jurat. ${ }^{93}$ Cuando la batlia pasó a ser de Honorat Berenguer Mercader, éste volvió a designarlo justícia civil el 22 de diciembre de 1468: «E aquí matex lo dit honorable batle donà e publicà per justícia civil, al dit hun any propvinent, lo honorable mossén Berenguer Mercader, cavaller, habitador de la dita ciutat, dat e nomenat a aquest offici per la parròquia de Santa Caterina». El día 25, «l'onorable mossén Berenguer Mercader, cavaller, menor de dies», prestaba juramento solemne «en poder e mans del dit honorable batle general». ${ }^{94}$

En 1471, año del fallecimiento del que fuera batle general, el oficio de justícia criminal era ejercido por su sobrino homónimo. ${ }^{95}$ De él había sido tutor en el tiempo que duró su orfandad, como también lo fue después del otro Berenguer Mercader de su familia, el joven doncel, que en esa misma fecha sería designado por primera vez jurat. ${ }^{96}$

De los datos anteriores se desprende una idea: la notoriedad en la ciudad de Valencia de los tres Berenguer Mercader coetáneos de Corella era bien desigual. Objetivamente, en modo alguno puede ser equiparable la fama del batle a la de los dos homónimos de su familia. Por ello, a nuestro modo de ver, en una obra que lleva por título Parlament [...] en casa de Berenguer Mercader, sin ningún elemento indicativo acerca de quién era éste, el lector de entonces había de dirigir su pensamiento al prócer.

\section{Los Mercader, los Pròxita, los Castellví}

La relevancia de Joan de Pròxita en la sociedad valenciana de la época de Corella, en el tiempo en que la batlia general estaba regida por Berenguer Mercader, está fuera de duda. El 6 de junio de 1462, domingo de Quinquagésima, en la ceremonia de juramento en la catedral de los nuevos jurats ante el batle, figura en primer lugar, como testigo importante, el «noble don Johan de Pròxita». ${ }^{97} \mathrm{El}$ año siguiente, él, segundo en rango de su familia tras Nicolau, era convocado de las cortes valencianas,

92 AMV, MC 37, f. 20(b)v (1462, septiembre, 28).

93 AMV, MC 37, ff. 126(b)v-127(b)r (1464, mayo, 19).

94 AMV, MC 38, f. 21(b)v y 35(b)r.

95 AMV, MC 39, f. 41r (1471, diciembre, 2).

96 AMV, MC 38, f. 197(b)r (1471, junio, 1).

97 AMV, MC 37, f. 1(b)r-2(b)r.

SCRIPTA, Revista internacional de literatura i cultura medieval i moderna, núm. 14 / desembre 2019 / pp. 1 - 33 ISSN: 2340-4841 · doi:10.7203/SCRIPTA.14.16357 
Agustín Rubio Vela. Sobre Berenguer Mercader, anfitrión del Parlament de Joan Roís de Corella, y demás contertulios

en las que participó. ${ }^{98}$ Su nombre aparece entre los de los más poderosos y potentados nobles y caballeros del reino. ${ }^{99}$

Al igual que Berenguer Mercader, Pròxita era persona muy adinerada. Ambos fueron servidores de la Corona. Aquél, desde las instituciones, como oficial de elevado rango. Éste, con su fortuna. Uno y otro apoyaron las complejas operaciones financieras de la monarquía, siempre necesitada de dinero. En 1469, entre los garantes de un elevado préstamo de diez mil florines concedido por la ciudad de Valencia al rey, se encontraban ambos: «Berengarius Mercader, maior natu, miles [...] Iohannes de Proxita, miles». Juan II y su hijo Fernando se referían a ellos el 3 de julio, desde Cervera: «...nos e lo dit rey de Sicilia haver donat en fermançes e principals obligats vosaltres, noble, magníffichs, amats e feels nostres don Joan de Pròxita, mossén Luýs de Cabanyelles, mossén Luýs de Vich, mossén Berenguer Mercader, major de dies...» ${ }^{100}$

Casado con Iolant Rabaça de Perellós, citada también como Iolant de Pròxita, Iolant Rabaça y Iolant de Perellós, ésta le sobrevivió ampliamente. ${ }^{101}$ Cuando falleció, en el testamento, la viuda nombró heredera universal a Isabel Magdalena de Centelles i de Pròxita, condesa de Oliva. ${ }^{102}$ Un matrimonio de alta alcurnia que Joan de Pròxita habría concertado para su única

98 AMV, Procesos de cortes, yy-20, ff. 7r-v (1463, febrero, 15). El 28 noviembre figura como asistente y testigo: «don Johan de Pròxita» (ibid., f. 180r).

99 El 14 de julio de 1464, en la cambra daurada de la sede del gobierno municipal, se reunían con los ediles y otros prohombres de la capital los siguientes: «comte de Coçentayna, vezcomte de Gayano, don Pedro d'Íxer, mossén Rodrigo Díez, mossén Carroç de Vilaragut, don Johan de Pròxita, mossén Perot Pardo, En Johan de Montpalau». El motivo de la reunión era la situación militar grave provocada por «la gent d'armes stranya que era entrada de les parts de Castella» en ayuda de don Jaime de Aragón, alzado en rebeldía contra el monarca (AMV, MC 37, f. 147(b)v-148(b)r).

100 AMV, Protocols, Jaume Ximeno II, t-2, s. fol. (1469, julio, 19). También id., ibid., 8-2, ff. 166v-175v (1470, octubre, 19).

101 «...que la noble senyora dona Yolant de Pròxida e de Perellós, muller del noble don Joan de Pròxida, quondam cavaller e habitador de la dita ciutat...» (AMV, MC 42, f. 156r-v; 1481, septiembre, 10); «...que la noble senyora dona Yolant de Pròxida e de Perellós, muller del noble don Joan de Pròxida, quondam, cavaller e habitador de la dita ciutat...» (id., MC 45, f. 66v; 1487, octubre, 19); «...ex peccuniis sibi traditis per nobilem et magnificam Yolante de Rabasa de Perellós, uxoris nobilis et magnifici Iohannis de Pròxita, habitatoris dicte civitatis...» (id., Protocols, Notals de Jaume Ximeno t-20, s. fol. (1488, enero, 19). «De la noble dona Na Yolant, muller de don Joan de Pròxita [...] vobis Yolanti de Perellós, uxori nobilis domini Ioannis de Pròxita, quondam (id., ibid., s. fol.; 1488, febrero, 27). «nobili Yolanti de Perellós, uxori nobilis Ioannes de Pròxita, quondam...» (id., Protocols 8-20, f. 23v: 1488). «De Dona Yolant de Pròxita [...] ...vos, nobilis et magniffica domina Yolans Rabaça de Perellós, uxor nobilis et magniffici Ioannis de Pròxita, quondam habitatoris Valentie...» (id., Protocols, Gaspar Ximeno, u-1, s. fol.; 1489, septiembre, 10); «a la noble dona Yolant de Perellós, muller del noble don Joan de Pròxida» (id., CCe I-106, f. 161v; 1490, marzo, 10).

102 «Item doní e paguí a la spectable dona Ysabel Magdalena de Sentelles e de Pròxita, comtessa de Oliva, muller del spectable don Ramon de Riusech, alias Saraffí de Sentelles, comte de Oliva [...] originalment carregats a la noble dona Iolant de Pròxita [...] Enaprés la dita noble dona Yolant de Perellós e de Pròxita és morta e ab son darrer testament [...] instituhí hereva universal la dita spectable dona Isabel Magdalena de Sentelles, comtessa de Oliva» (AMV, Quitaments de Censals W-8 (1480-1493), f. 193v). Según), era hija única y su padre «la casà el 1476 amb el noble lletraferit mossén Serafí de Centelles».

SCRIPTA, Revista internacional de literatura i cultura medieval i moderna, núm. 14 / desembre 2019 / pp. 1 - 33 ISSN: 2340-4841 · doi:10.7203/SCRIPTA.14.16357 
Agustín Rubio Vela. Sobre Berenguer Mercader, anfitrión del Parlament de Joan Roís de Corella, y demás contertulios

hija en 1476, el año de su fallecimiento (Soler 2014: 274). El dietarista Miralles, que en 1471 se hizo eco del óbito del que fuera batle, también registró, por partida doble, el de Pròxita: «Com morí don Johan de Pròxita. [...] disapte a .X. de agost morí lo dit don Johan de Pròxita»; «lo disapte aprés, a .X. de agost, morí don Johan de Pròxita, noble» (Rodrigo Lizondo 2011: 443 y 445).

Diez años antes del fallecimiento, en abril de 1466, en una carta de los jurats a los missatgers de la ciudad enviados a Segorbe, se indicaba que «los magnífichs don Johan de Pròxita, micer Johan de Galach e mossén lo racional són stats ab la senyora infanta, e, haüd algun rahonament ab ella, han-la supplicada en aquests affers no vulla fer novitat alguna. À ls promés sobreseure en açò, no fahent novitat alguna tres o quatre dies». ${ }^{103}$ Se trataba de un conflicto de intereses entre Valencia y Beatriz de Pimentel, viuda del infante Enrique, por «la teneó e custòdia del castell» de Segorbe, ciudad ésta bajo jurisdicción de aquélla y de su hijo. En septiembre del año siguiente, el rey intervenía en el asunto, dando instrucciones a su vicecanciller para que el castillo fuera puesto bajo custodia de una de estas tres personas: «don Johan de Pròxida o mossén Luís de Castellví o mossén Johan de Castellví». La respuesta de los ediles de Valencia fue negativa: «ha per clar e no dubte gents que los dits don Johan de Pròxida e mossén Luís e mossén Johan de Castellví, e cascun d'ells, encara que sien persones notables, són axí affectats e devots a la senyora infanta e senyor infant, son fill, que no seria àls sinó per via indirecta metre realment lo dit castell en lur poder e mà». De ahí su contundente respuesta: «per cosa del món no acceptarien algú dels dessús tres nomenats, sinó que s’i nomenàs persona no sospitosa». ${ }^{104}$ Lo que indica que entre Pròxita y los Castellví había un vínculo político: eran personas de confianza del rey Juan II y «affectats e devots» de su cuñada y sobrino. Ahora bien, ¿quién era ese Lluís de Castellví?

\section{Lluís de Castellví. Otro caso de homonimia}

Tradicionalmente se ha identificado al Lluís de Castellví del Parlament con el marido de Violant de Montpalau. Al igual que Ferrando Francés (2013: 641) y Chiner Gimeno (2014: 165 y 167), Soler acepta esta identificación: «Mossén Lluís de Castellví i Esplugues (c. 1435-1481), marit de Violant de Montpalau (†1508) des del 27 de gener del 1462, i parent llunyà de Roís de Corella -per la branca dels Esplugues-, és el quart participant del Parlament literari de donzells i cavallers idealitzat per l'estudiant de teologia.» Tras indicar que «quan se'l cita en el Parlament (c. 1462)» era todavía doncel, avisa de que «no l’hem de confondre amb un altre donzell Lluís de Castellví, casat amb Elionor Tolrà, que fou primer baró de Benimuslem. Ni tampoc amb el seu cosí germà Lluís de Castellví i Mercader, cavaller de Sant Jaume i cinqué senyor de Carlet,

103 AMV, LM 26, f. 205v (1466, abril, 25).

104 AMV, LM 26, f. $221 \mathrm{r}-\mathrm{v}$.

SCRIPTA, Revista internacional de literatura i cultura medieval i moderna, núm. 14 / desembre 2019 / pp. 1 - 33 ISSN: 2340-4841 · doi:10.7203/SCRIPTA.14.16357 
Agustín Rubio Vela. Sobre Berenguer Mercader, anfitrión del Parlament de Joan Roís de Corella, y demás contertulios

casat el 1442 amb Elisabet-Joan de Montsoriu, i cunyat del batle Honorat-Joan Mercader» (2014: 268-269).

Confundirlo con el primero es imposible, puesto que en 1462 ya llevaba dos años en la sepultura. El 19 de julio de 1460, en Carlet, era leído su testamento, dictado allí mismo dieciocho días antes: «confecto in loco de Carlet, termini ville Algezire prima die mensis iulii anno a nativitate Domini $\mathrm{M}^{\circ} \mathrm{CCCC}^{\circ} \mathrm{LX}^{\circ} \gg,{ }^{105}$ dejando viuda a Elionor de Tolsà, y dos hijos varones, mossén Perot y Lluís de Castellví, ${ }^{106}$ que fueron declarados herederos.

Quien sí vivía en 1462 era Lluís de Castellví, caballero santiaguista y señor de Carlet, que Soler excluye como contertulio de Corella en el Parlament en las líneas que hemos reproducido anteriormente. En ellas se detectan errores varios, el primero de los cuales es el de la mujer con la que contrajo matrimonio, que no fue Elisabet-Joan de Montsoriu, sino Isabel Suau: «ego, Ysabel Suau, uxor nobilis Ludovici de Castellví, militis ordinis et militie Sancti Iacobi de Spata, domini loci de Carlet, habitatoris civitatis Valentie». ${ }^{107}$ Fue él, Lluís de Castellví, señor de Carlet, el padre de Elionor de Castellví, con la que contrajo matrimonio Honorat Berenguer Mercader, cuyo nombre de pila el citado autor cambia por el de Honorat-Joan. Así pues, Lluís de Castellví, hijo de una Mercader, era consuegro del batle Berenguer Mercader y padre político de Honorat Berenguer Mercader, convertido por Soler en su cuñado. ${ }^{108}$ De esa estrecha relación familiar entre el Lluís de Castellví, caballero de la orden de Santiago, y el batle general, se hizo eco el dietarista Miralles al dar la noticia de la muerte de este último el 28 de septiembre de 1471: «Avia tres anys que avia fet testament, e que avia renunciat la ballia al fill major, genre de mossén Loís de Castelví» (Rodrigo Lizondo 2011: 405).

Son datos que nos llevan a considerar verosímil la hipótesis de que fuese él el Lluís de Castellví del Parlament y el batle general el Berenguer Mercader anfitrión. A los que han de unirse otros, como el de la relación documentada entre Lluís y Joan de Castellví y Joan de Pròxita como servidores del rey y de su cuñada Beatriz en el conflicto entre ésta y la ciudad de Valencia. No hay duda de que el primero era mossén Lluís, el caballero de la orden de Santiago y señor de Carlet, hijo de Elionor Mercader y consuegro del batle Berenguer Mercader, puesto que entonces -1468- seguía siendo doncel su homónimo, el marido de Iolant de Montpalau. ${ }^{109}$

105 AMV, Protocols, Jaume Beneyto, r-18, s. fol. (1462, abril, 7).

106 Este otro Lluís de Castellví no es mencionado por Soler.

107 AMV, Protocols, Jaume Ximeno t-19, s. fol. (1487, noviembre, 15).

108 Curiosamente escribe a continuación: «Resolta succintament la possible confusió onomàstica, afegirem...» (Soler 2014: 269)

109 Cuando se aprobaba una operación censal: «sia fet carregament a l’honorable En Loís de Castellví, donzell, fill de l'honorable mossén Pere de Castellví...» (AMV, MC 38, f. 177r [primera foliación]; 1468, abril, 9). Dos años más tarde era ya caballero: «Ludovicus de Castellví, miles, filius honorabilis Petri de Castellví, militis, et pro eo Petrus de Sancta

SCRIPTA, Revista internacional de literatura i cultura medieval i moderna, núm. 14 / desembre 2019 / pp. 1 - 33 ISSN: 2340-4841 · doi:10.7203/SCRIPTA.14.16357 
Agustín Rubio Vela. Sobre Berenguer Mercader, anfitrión del Parlament de Joan Roís de Corella, y demás contertulios

Finalmente, es patente que la relación familiar entre este último y Joan Escrivà, esgrimida para considerarlo contertulio de Corella, fue posterior a la muerte tanto del batle Berenguer Mercader como de don Joan de Próxita: Escrivà y Lluís fueron concuñados en 1479, año del matrimonio de aquél con Beatriu de Montpalau, hermana de Iolant (véase nota núm. 11).

\section{Conclusiones, sugerencias y nota sobre cronología}

Los nombres de tres de los «hòmens d'estat» que participaron en el Parlament, Berenguer Mercader, Joan de Pròxita y Lluís de Castellví, coinciden con los de tres personalidades de gran relieve, fieles servidores de la Corona, y con vínculos familiares entre sí. Lo cual, unido a la amistad documentada entre los Corella y los Pròxita, ${ }^{110}$ ayuda a comprender la proximidad entre el joven poeta y don Joan de Pròxita, de quien consta su interés por la poesía, ${ }^{111}$ así como la presencia de ambos en la casa del batle general, que en su juventud había estado en la corte del Magnánimo, en plena efervescencia del humanismo italiano, y cuyas intervenciones públicas merecían elogios por su oratoria elegante y expresiones ornadas.

Los dos más jóvenes contertulios, Guillem Ramon de Vilarrasa y Joan Escrivà, fueron amigos de Corella y de su misma generación. El primero, que, según Soler, nació hacia 1436 y murió antes de 1506 (2014: 264), ${ }^{112}$ volvió a Valencia en 1461, tras la muerte del príncipe de Viana, a quien sirvió. Se ha dicho que posiblemente fuera la persona que puso en contacto al infortunado Carlos de Aragón con Corella (Riquer 1980: III, 315), propiciando el célebre Debat epistolar entre ambos. En cuanto al segundo, Joan Escrivà, poeta cuatrocentista, nacido hacia 1435 según Parisi (2008-2009: 66) y considerado por Riquer «un dels millors de la seva època» (1980: III, 354-364; y 1993), sabemos que en 1461, cuando tenía unos veintiseis años, su vida y estado dieron un giro radical; de ser un segundón sin recursos pasó a ser un rico

Cruce, scutiferus, procurator...» (AMV, Protocols, Bernat Santfelin 13-21, s. fol.; 1470, septiembre, 18).

110 La madre del poeta, en su primer testamento, de 1451, nombró tutor de sus hijos a mossén Lluís de Calatayud, que era tío de Joan (Ferrando Francés 2013: 643; Soler 2014: 273-274). En 1453 se documenta una Elionor de Calatayud, viuda de Joan de Pròxita, hermana de Lluís de Calatayud: «...cum assensu firma et voluntate nobilium Ludovici de Calatayú, militis, Elionoris, uxor quondam nobilis Iohannis de Proxita, et Ysabelis, uxor quondam Petri Maça de Liçana, militum, ut fratris et sororum nobilis Michaelis Iohannis de Calatayú, militis, quondam, ac heredum et succedentium...» (AMV, Protocols, Jaume Beneyto, r-15, s. fol.; 1453, abril, 18). También consta que en 1454 Joan de Pròxita, junto a dos más, vendieron a «Aldonça Roís de Corella, vídua d’Ausiàs Roís de Corella, 150 sous censals anuals de violari durant les vides dels seus fills Joan i Lluís Roís de Corella, donzells» (Chiner Gimeno 2014: 167).

111 Cabe recordar que en el célebre certamen mariano de 1474, los nombres de Joan de Pròxita y de Lluís de Castellví aparecen juntos: «Jutges tenint, de gran magnificència, lo cabiscol de la Seu, molt insigne, y ab don Johan de Pròxida, lo noble, mossén Luís de Castellví, magnífich». La relación entre él y Pròxita apunta a la posibilidad de que Lluís fuera el señor de Carlet, y no su homónimo, el marido de Iolant de Montpalau.

112 Consta que en 1502 hizo testamento (Chiner Gimeno 2014: 168).

SCRIPTA, Revista internacional de literatura i cultura medieval i moderna, núm. 14 / desembre 2019 / pp. 1 - 33 ISSN: 2340-4841 · doi:10.7203/SCRIPTA.14.16357 
Agustín Rubio Vela. Sobre Berenguer Mercader, anfitrión del Parlament de Joan Roís de Corella, y demás contertulios

propietario, al descubrir que era el heredero de la gran fortuna de su tío, Ferrer Ram, tras el hallazgo del testamento de éste, que su madre le había ocultado durante más de una década (Rubio Vela 2014: 47-51, 58 y 59).

El análisis documental indica que, de los cinco contertulios de Joan Roís de Corella en el Parlament, tres fueron personas de gran relieve social, caballeros -Mercader, el noble Pròxita y Castellví-, mayores que él, y los otros dos -Vilarrasa y Escrivà-, donceles, de una edad próxima a la suya, con los que le unía gran amistad. Desde esta perspectiva cabría hacer la lectura de la frase en que el autor, al anunciar que se disponía a recitar como cronista el coloquio que en días pasados hubo entre aquellos «hòmens d'estat», afirmaba que ocultar sus nombres «seria a la sua ínclita fama haver enveja e a vertadera amistat girar les spatles». Fama y amistad. Los lectores de la época, conocedores de todos ellos, tendrían pocas dudas acerca de quiénes eran los destinatarios de aquel elogio - «la sua ínclita fama»-, en el que Corella no se incluía a sí mismo, y de quiénes eran los unidos a él por una «vertadera amistat».

¿Cuándo? Las hipótesis sobre la cronología de la obra son variadas: escrita antes de 1469/1471 según Riquer (1980: III, 314 y 315), antes de 1460 según Cingolani (1998: 25), en los años ochenta del siglo XV según Guia i Marín (2003), «abans de gener de 1459» según Ferrando (2013: 639 y 640), «a finals de la dècada dels anys cinquanta» según Chiner Gimeno (2014: 166), o en torno a 1462 según Soler (2014: 253 y 256).

El problema de la homonimia, que ha permitido cuestionar que el batle y el señor de Carlet fuesen los citados en la velada literaria, no se da en el caso de Pròxita. Y ello es importante desde una perspectiva cronológica, pues la obra de Roís de Corella debió de ser escrita después de que el noble adquiriera el 'don' con el que figura en el texto, con el que lo hemos documentado por primera vez en 1458. Según se ha visto, en julio de este año, don Joan de Pròxita se encontraba en Capua y a finales de agosto en Roma. Por otro lado, el hecho de que Guillem Ramon de Vilarrasa estuviera en Sicilia en enero de 1459, y que hasta avanzado el año 1461 no volviera a la ciudad de Valencia, donde compró una casa en diciembre y concertó su matrimonio en enero del siguiente (Rubio Vela 2016: 99-100), nos lleva a pensar que el Parlament corelliano debió de escribirse a partir del citado año de 1461, el del retorno de éste a la ciudad, y antes del fallecimiento en 1471 del batle general. Desde luego, con anterioridad a la muerte de Pròxita en 1476. No es posible, con los datos disponibles, precisar más.

Es obligado, no obstante, subrayar la importancia de respaldar con documentación concreta y argumentación fiable las afirmaciones cronológicas relativas a la incierta fecha del Parlament. Se han hecho aseveraciones basadas en datos infundados, que es necesario rectificar para que no sigan exhibiéndose como prueba. A las señaladas en páginas anteriores sobre las inexistentes celebraciones matrimoniales en 1460 de los donceles Berenguer Mercader y Joan Escrivà (Soler 2014: 256 y 260), han de añadirse algunas otras no menos equivocadas, como la de que «si el Parlament s'hagués produït després de setembre del 1461, Corella difícilment hauria

SCRIPTA, Revista internacional de literatura i cultura medieval i moderna, núm. 14 / desembre 2019 / pp. 1 - 33 ISSN: 2340-4841 $\cdot$ doi:10.7203/SCRIPTA.14.16357 
Agustín Rubio Vela. Sobre Berenguer Mercader, anfitrión del Parlament de Joan Roís de Corella, y demás contertulios

deixat d'atorgar-li [a Guillem Ramon] el tractament de cavaller» (Ferrando 2013: 641 y 642), que se basa en un dato completamente erróneo: está probado que Vilarrasa no era todavía caballero. El 15 de febrero de 1463, «En Guillem Ramon de Vilarrasa, donzell», era convocado a las cortes valencianas «pro brachio domicellorum» (Rubio Vela 2016: 100), y seguía siéndolo aún el 1 de octubre de 1467: «vobis, honorabili Guillermo Raymundi de Vilarassa, domicello, habitatori dicte civitati». ${ }^{113}$

Tampoco pueden aceptarse sospechas como la de que Corella escribió el Parlament con anterioridad a la fecha en que Joan Escrivà dejó de llamarse así para adoptar el nombre de Joan Ram Escrivà. Ese año sería supuestamente terminus ante quem de la obra: «Joan Ram Escrivà ja figura amb aquesta denominació en documents de 1463 i ens sembla difícil que el seu amic el nomenara tant sols 'Joan Escrivà' si el Parlament fóra posterior a aquest any» (Chiner 2013: 166). ${ }^{114}$ Sabemos, sin embargo, que siguió usando su antiguo nombre con posterioridad. No sólo lo demuestra el Jardinet, texto fechado un cuarto de siglo después, en el que hay cuatro piezas suyas, donde aparece como «mossén Joan Escrivà, cavaller» (Rubio Vela 2014: 59). Mucho más concluyente resulta al respecto la información que él mismo nos proporciona en una hoja suelta, escrita de su propia mano y fechada el 27 de febrero de 1486, conservada en el interior de un libro notarial de Jaume Ximeno, entonces escrivà de la Sala, a quien va dirigida: «Yo, Juhan Scrivà, promet a vós, magnífich En Jaume Ximeno, scrivà de la Sala de la insigne ciutat de València, que d'ací a XV jorns primervinents vos restituhiré la carta del caregament de $\mathrm{XI}^{\mathrm{m}}$ sous fet a mosén Salelles, lo vell, hi encara, si mester serà, qualssevol altres clàusules faents per lo cit censal. E per testimoni de veritat vos faç lo present albarà de mà mia. XXVII de febrer, any MCCCCLXXXVI». ${ }^{115}$ Por su interés, reproducimos el original de este documento en fotografía anexa.

113 AMV, Protocols, Jaume Beneyto, r-20, s. fol.

114 Realmente fue en 1461 cuando adoptó el apellido Ram, obligado por el testamento de su tío.

115 AMV, Protocols, Jaume Ximeno 8-18. En el reverso, el notario escribió tras recibir la nota manuscrita: «Albarà d’En Joan Ram, mestre racional, pres per manament dels magnífichs En Pere de Soler e d'En Pere Çacruella, jurats, present En Bernat Dassió, notari, lochtinent del scrivà, qui anà ab lo mestre racional a casa mia, a l'ort de fora ciutat». 
Agustín Rubio Vela. Sobre Berenguer Mercader, anfitrión del Parlament de Joan Roís de Corella, y demás contertulios

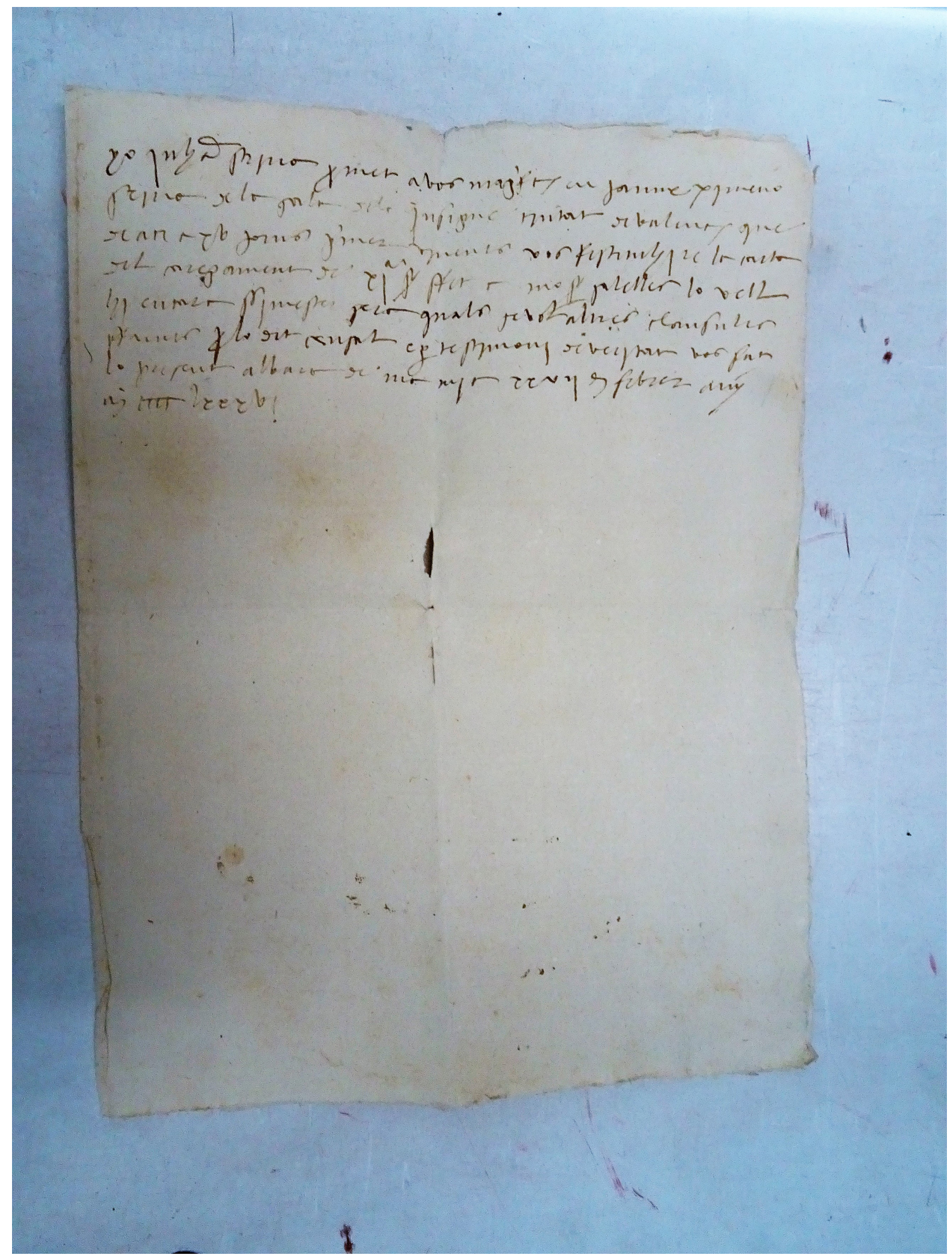

AMV, Protocols, Jaume Ximeno 8-18.

SCRIPTA, Revista internacional de literatura i cultura medieval i moderna, núm. 14 / desembre 2019 / pp. 1 - 33 ISSN: 2340-4841 · doi:10.7203/SCRIPTA.14.16357 
Agustín Rubio Vela. Sobre Berenguer Mercader, anfitrión del Parlament de Joan Roís de Corella, y demás contertulios

\section{Bibliografía}

Carbonell, J. (ed.) (1983) Joan Roís de Corella: Obra profana, Valencia, Eliseu Climent.

Cassanyes Roig, A. (2018) Antoni Cerdà (c. 1390-1459). Poder polític i promoció eclesiàstica a mitjans del segle $X V$. Tesi doctoral, Universitat de Lleida.

Cingolani, S. M. (1998) Joan Roís de Corella: La importància de dir-se honest, Valencia, Eliseu Climent.

Ferrando Francés, A. (2013) «Les relacions literàries de Joan Roís de Corella», Afers, 76, 635-65.

Fuster, Joan (1968) «Lectors i escriptors en la València del segle XV», en Obres completes, I. Llengua, literatura, història, Barcelona, Edicions 62.

Garín Ortiz de Taranco, F. Ma et alii (1983) Catálogo monumental de la ciudad de Valencia, Caixa d'Estalvis de València, València.

Gual Camarena, M. (1951) Las treguas de Majano entre Aragón, Navarra y Castilla (1430), Facultad de Filosofía y Letras, Buenos Aires.

Guia i Marín, J. (2003) «Dades documentals d'interès literari (València, segle XV)», en Anna M. Compagna Perrone Capano, Alfonsina De Benedetto y Núria Puigdevall (eds.): Momenti di Cultura Catalana in un Millennio, Nápoles, I, pp. 201-222. http://www.cervantesvirtual.com/nd/ ark:/59851/bmcr78p9

Guinot, Salvador (1921) Parlament de casa Mercader i Tragedia de Caldesa, novelas de J. Roiç de Corella. Siglo XV, Castellón, Est. Tip. de hijos de J. Armengot.

Gustà, Marina (ed.) (1980) Joan Roís de Corella: Tragèdia de Caldesa i altres proses, Barcelona, Edicions 62.

Iborra, Joan (ed.) (2000) Berenguer de Puigpardines: Sumari d'Espanya, Valencia, Universitat de València.

López Quiles, A. (2014) «La proposta sapiencial de Corella», en A. Ferrando (ed.), Joan Roís de Corella i el seu món, Valencia, Institució Alfons el Magnànim, pp. 389-422.

López Rodríguez, C. (2005) Nobleza y poder politico en el reino de Valencia (1416-446), Valencia, Universitat de València.

Martos, Josep Lluís (2001) Les proses mitològiques de Joan Roís de Corella, Alacant/Barcelona, IIFV, Publicacions de l'Abadia de Montserrat.

Mérida Jiménez, M. (1999) «Comentaris a l'entorn de la primera difusió impresa de Joan Roís de Corella», en V. Martines (ed.): Estudis sobre Joan Roís de Corella, Alcoi, Ed. Marfil.

Miquel y Planas, R. (1913) Obres de J. Roiç de Corella, Barcelona, Biblioteca Catalana.

Parisi, Ivan (2008-2009) «Els Escrivà, parents dels Borja: una continuació», Revista Borja. Revista de l'Institut Internacional d'Estudis Borgians, 2 [= Actes del II Simposi Internacional sobre els Borja], pp. 55-79.

Pérez Pérez, Desamparados (ed.) (1971) El Llibre Blanch de la Governació, Valencia, Acción Bibliográfica Valenciana.

SCRIPTA, Revista internacional de literatura i cultura medieval i moderna, núm. 14 / desembre 2019 / pp. 1 - 33 ISSN: 2340-4841 · doi:10.7203/SCRIPTA.14.16357 
Agustín Rubio Vela. Sobre Berenguer Mercader, anfitrión del Parlament de Joan Roís de Corella, y demás contertulios

Riquer, Martí de (1980) Història de la literatura catalana, Barcelona, Ariel (2 ed.), 3 vols.

Rius Serra, J. (ed.) (1948-1958) Regesto ibérico de Calixto III, Barcelona, CSIC, 2 vols.

Rodrigo Lizondo, M. (ed.) (2011) Melcior Miralles: Crònica i dietari del capellà d'Alfons el Magnánim, Universitat de València.

Rubio Vela, A. (ed.) (1998) Epistolari de la València medieval (II), València/Barcelona, IIFV-Publicacions de l'Abadia de Montserrat, .

- (2000), Alfons de Borja y la ciudad de Valencia (1419-1458). Colección de documentos del Archivo Histórico Municipal, Valencia, Fundación Valencia III Milenio.

- (2013) «El context històric de Joan Roís de Corella. Tríptic documental sobre el seu entorn», Afers 76, pp. 593-616.

_ (2014) «Circunstancia familiar y entrada en la vida política del joven poeta valenciano Joan Escrivà (1461-1462)», Scripta. Revista internacional de literatura i cultura medieval i moderna, núm. 3, pp. 46-70.

- (2016) Valencia, el príncipe de Viana y Juan II. Un patriciado ante la crisis política de la monarquía (1460-1461), Valencia, Gráficas Papallona.

- (2017) Joan Aguilar, escrivà de la Sala de la ciudad de Valencia (1423-1425). Voluntad de estilo en las misivas municipales, Valencia, Gráficas Papallona.

Simó, Trinidad \& Teixidor de Otto, $\mathrm{M}^{\mathrm{a}}$ Jesús (1996): La vivienda y la calle. La calle de Cavallers de Valencia como ejemplo de desarrollo urbano, Valencia, Edicions Alfons el Magnànim.

Soler, Abel (2014), Joan Roís de Corella (1435-1497). Sintesi biogräfica i aportació documental, Valencia, Acadèmia Valenciana de la Llengua.

Tintó Sala, Margarita (1979) Cartas del baile general de Valencia, Joan Mercader, al rey Fernando de Antequera, Valencia, Institució Alfons el Magnànim.

Villalmanzo, Jesús (1995) Joanot Martorell. Biografía ilustrada y diplomatario, Valencia, Ajuntament de València.

—_. (1999) Ausias March. Colección documental, Valencia, Institució Alfons el Magnànim.

Wittlin, Curt (1998) «La biblioteca de la família Mercader de València l'any 1489», Caplletra 24, pp. 93-104. 